OPEN ACCESS

Edited by:

Fernando Cendes,

Universidade Estadual de

Campinas, Brazil

Reviewed by:

Luiz Eduardo Betting,

Sao Paulo State University, Brazil

Stefano Seri,

Aston University,

United Kingdom

${ }^{*}$ Correspondence:

Udaya Seneviratne

udaya.seneviratne@monash.edu

Specialty section:

This article was submitted

to Epilepsy,

a section of the journal

Frontiers in Neurology

Received: 20 July 2017 Accepted: 07 September 2017 Published: 25 September 2017

Citation:

Seneviratne U, Cook MJ and D'Souza WJ (2017)

Electroencephalography

in the Diagnosis of Genetic Generalized Epilepsy Syndromes.

Front. Neurol. 8:499. doi: 10.3389/fneur.2017.00499

\section{Electroencephalography in the Diagnosis of Genetic Generalized Epilepsy Syndromes}

\author{
Udaya Seneviratne ${ }^{1,2 *}$, Mark J. Cook ${ }^{1}$ and Wendyl Jude D'Souza ${ }^{1}$ \\ ${ }^{1}$ Department of Medicine, St. Vincent's Hospital, The University of Melbourne, Melbourne, VIC, Australia, ${ }^{2}$ Department of \\ Neuroscience, Monash Medical Centre, Melbourne, VIC, Australia
}

Genetic generalized epilepsy (GGE) consists of several syndromes diagnosed and classified on the basis of clinical features and electroencephalographic (EEG) abnormalities. The main EEG feature of GGE is bilateral, synchronous, symmetric, and generalized spike-wave complex. Other classic EEG abnormalities are polyspikes, epileptiform K-complexes and sleep spindles, polyspike-wave discharges, occipital intermittent rhythmic delta activity, eye-closure sensitivity, fixation-off sensitivity, and photoparoxysmal response. However, admixed with typical changes, atypical epileptiform discharges are also commonly seen in GGE. There are circadian variations of generalized epileptiform discharges. Sleep, sleep deprivation, hyperventilation, intermittent photic stimulation, eye closure, and fixation-off are often used as activation techniques to increase the diagnostic yield of EEG recordings. Reflex seizure-related EEG abnormalities can be elicited by the use of triggers such as cognitive tasks and pattern stimulation during the EEG recording in selected patients. Distinct electrographic abnormalities to help classification can be identified among different electroclinical syndromes.

Keywords: spike-wave, polyspike, sleep, photoparoxysmal response, myoclonic seizure, absence seizure, tonicclonic seizure, circadian

\section{INTRODUCTION}

Genetic generalized epilepsy (GGE) encompasses several electroclinical syndromes diagnosed and classified according to clinical features and electroencephalographic (EEG) characteristics (1-3). The EEG hallmark of GGE is bilateral synchronous, symmetrical, and generalized spike-wave (GSW) discharges. Polyspikes and polyspike-wave discharges are also commonly seen in GGE. Fixationoff sensitivity (FOS), eye-closure sensitivity, photoparoxysmal response (PPR), epileptiform K-complexes/sleep spindles, and occipital intermittent rhythmic delta activity (OIRDA) are among the spectrum of abnormalities described in GGE (4).

In this review, we will be discussing the ictal and the interictal EEG abnormalities in GGE. We will also focus on the electrographic differences among different GGE syndromes, factors affecting the yield of EEG, and diagnostic pitfalls.

\section{INTERICTAL VERSUS ICTAL ABNORMALITIES}

Interictal EEG abnormalities are defined as "epileptiform patterns occurring singly or in bursts lasting at most a few seconds," whereas ictal rhythms consist of "repetitive EEG discharges with a relatively abrupt onset and termination and characteristic pattern of evolution lasting at least several seconds" (5). Subclinical seizure activity refers to EEG seizure patterns not accompanied by clinical signs and symptoms (5). However, in absence seizures, differentiating interictal from 
ictal epileptiform discharges can be difficult as those discharges demonstrate monomorphic rhythmicity with little evolution. Consequently, the distinction between ictal and interictal activity depends on how long it lasts and clinical features, particularly impairment of consciousness during the discharge. Researchers have used several testing methods, including reaction time and motor tasks to study cognition and the degree of consciousness during spike-wave discharges (6).

Consequently, there is no consensus on the duration of the GSW paroxysm that defines an absence seizure. Sadleir et al. diagnosed absence seizures based on two criteria: (1) GSW activity of any duration when accompanied by clinical signs and (2) GSW lasting $>2$ s even if not accompanied by clinical correlates. Discharges of $<2$-s duration without clinical signs were identified as interictal fragments (7). A more recent study considered GSW bursts lasting 3 or more seconds, with or without clinical signs, as an absence seizure (8).

Conversely, myoclonic seizures and generalized tonic-clonic seizures demonstrate well-characterized EEG changes and the distinction from interictal EEG abnormalities is more unequivocal (4).

\section{INTERICTAL ABNORMALITIES}

\section{Spike-Wave Complex Morphology and Amplitude}

Gibbs et al. published the first detailed analysis of the spike-wave complex $(9,10)$. Subsequently, a more detailed analysis has revealed 3 components of the spike (spike 1, positive transient, and spike 2) (11). The surface negative spike 1 is of low amplitude $(25-50 \mu \mathrm{V})$ and brief duration $(10 \mathrm{~ms})$. The second component is a positive transient of $100-150 \mathrm{~ms}$. It is followed by spike 2 of negative polarity lasting 30-60 ms with frontal amplitude maxima. The dome-shaped wave of negative polarity, which follows the spike, lasts 150-200 ms (Figure 1) (11). However, spike 1 is seen less consistently than spike 2 (12).

A recent study based on 24-h ambulatory EEGs found $96.4 \%$ of generalized epileptiform discharges to be symmetric. However, the typical morphology was observed in only $24 \%$ (13).

\section{Topography}

Typically, the maximum amplitude is seen over the frontocentral region. With the use of 3-dimensional field potential maps, researchers were able to demonstrate that the amplitude maximum of spikes was over the frontal region involving anterior and midline electrodes (14). Using quantitative EEG analysis, Clemens and co-workers were able to demonstrate increased activity over the prefrontal region in patients diagnosed with GGE (15). The field maxima during absence seizures are usually detected at Fz electrode with lateral spread to F3, F4, and posterior spread to $\mathrm{Cz}$ electrode (16). The amplitude maximum of the spike-wave complex is most frequently observed in the frontocentral region (96.3\%), followed by frontopolar (2.4\%), and occipital (1.3\%) regions (13).

Further insights into topography have been revealed in studies using quantitative EEG techniques. The source localization of epileptiform discharges on dense array EEG in juvenile myoclonic epilepsy (JME) detected activity in the orbitofrontal and medial frontopolar cortex (17). Another study using three techniques of source imaging analysis found anterior cingulate cortex and medial frontal gyrus as the primary anatomical sources of GSW discharges in GGE (18).

\section{Regularity}

In EEG, regularity is defined as "waves or complexes of approximately constant period and relatively uniform appearance" (5).
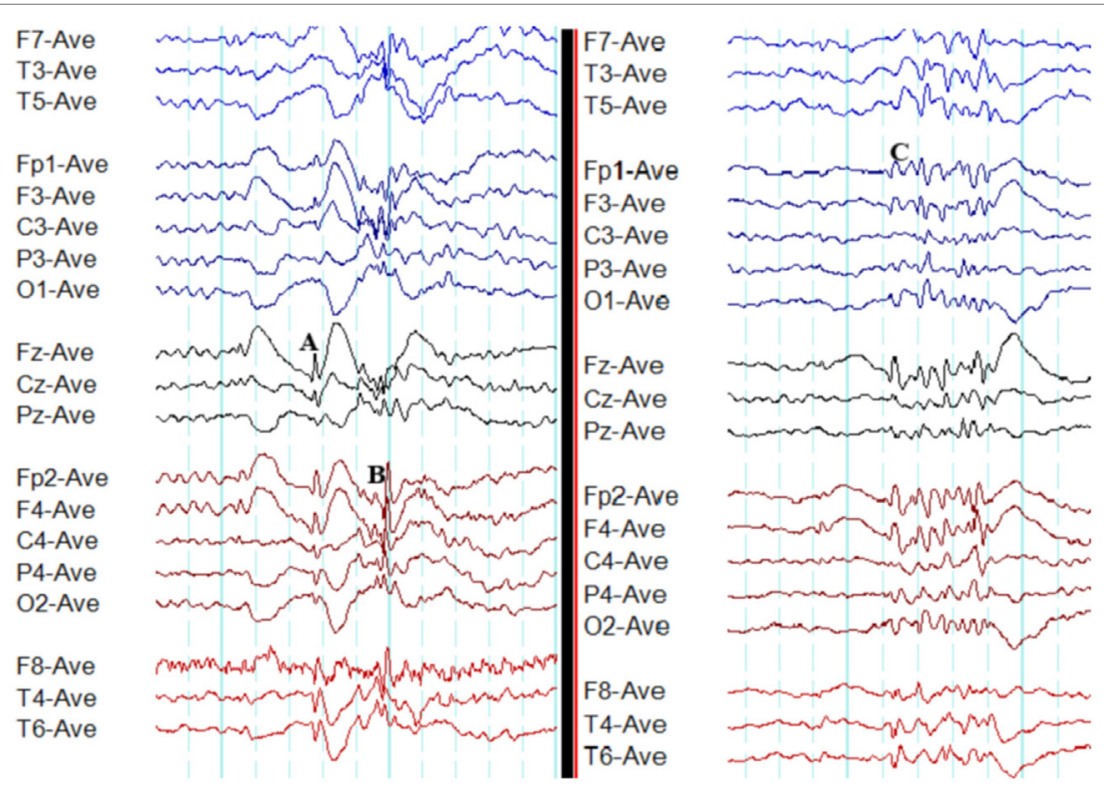

FIGURE 1 | Typical interictal epileptiform discharges in genetic generalized epilepsy. Note bilateral, symmetrical, and synchronous spike-wave discharges (A), polyspike-wave discharges (B), and polyspikes (C). 
The classic electrographic feature in GGE is regular and rhythmic GSW discharges. Nonetheless, a recent study has reported that $60 \%$ of GSW paroxysms are irregular (13).

\section{Frequency of Discharges}

The typical $3 \mathrm{~Hz}$ spike-wave activity characteristic of absence seizures was first described by Gibbs and collaborators (9). The fast spike-wave activity of $>3.5 \mathrm{~Hz}$ is usually seen in juvenile myoclonic epilepsy (JME) (19). The spike-wave discharge frequency in juvenile absence epilepsy (JAE) (mean $3.25 \mathrm{~Hz}$ ) is faster than childhood absence epilepsy (CAE) and slower than JME (7). In spike-wave paroxysms, the frequency is not constant throughout. The initial frequency is slightly faster and then it becomes more stable, slower, and regular (20).

\section{Background}

In GGE, typically, epileptiform discharges emerge from a normal background (2). Generalized epileptiform discharges occurring on a slow and disorganized background raise the possibility of an epileptic encephalopathy $(21,22)$.

\section{Polyspikes and Polyspike-Wave Discharges}

Polyspikes are characterized by a run of two or more spikes, whereas the polyspike-wave complex consists of polyspikes followed by slow waves (5). In GGE, polyspikes usually occur in the form of high-amplitude rhythmic bursts with synchronized and generalized distribution (Figure 1).

\section{Photoparoxysmal Response}

This is an abnormal response manifesting with the generation of spike-wave complexes, polyspikes, or polyspike-wave discharges during intermittent photic stimulation (5). The PPR is under the influence of several confounding variables including age, sex, ethnicity, genetics, antiepileptic medication use, state of alertness (sleep vs wakefulness), sleep deprivation, and the stimulation technique. There are three grades of PPR: (1) posterior stimulus dependent response, (2) posterior stimulus independent response, and (3) generalized response (23). The response to photic stimulation is defined as self-sustained when the epileptiform discharges outlast the stimulus by $\geq 100 \mathrm{~ms}$ (24). It is most frequently detected in JME (83\%) followed by CAE (21\%) and JAE (25\%) (7). However, PPR can also be elicited in $0.3-4 \%$ adults without a history of epilepsy $(25,26)$. It is detected more frequently $(14.2 \%)$ in asymptomatic children (27). The influence of various confounders including stimulation techniques may explain the wide range of results reported in the literature.

\section{Eye-Closure Sensitivity}

Epileptiform discharges characteristic of eye-closure sensitivity emerge within 1-3 s of eye closure and last for 1-4 s. However, the discharges do not persist for the total duration when eyes remain closed (Figure 2). Photosensitivity and eye-closure sensitivity are related phenomena (28).

\section{Fixation-Off Sensitivity}

Epileptiform discharges, generalized or occipital, triggered by the elimination of fixation and central vision are the hallmarks of FOS (29). This abnormality needs to be distinguished from photosensitivity and eye-closure sensitivity. In FOS, epileptiform discharges persist for the total duration of eye closure and disappear on eye opening (Figure 2) (29). To confirm FOS, central vision and fixation should be abolished with the application of spherical lenses, Frenzel lenses, or Ganzfeld stimulation technique (30). FOS has been described in GGE and occipital epilepsy (30). In some patients, photosensitivity and FOS coexist (31).

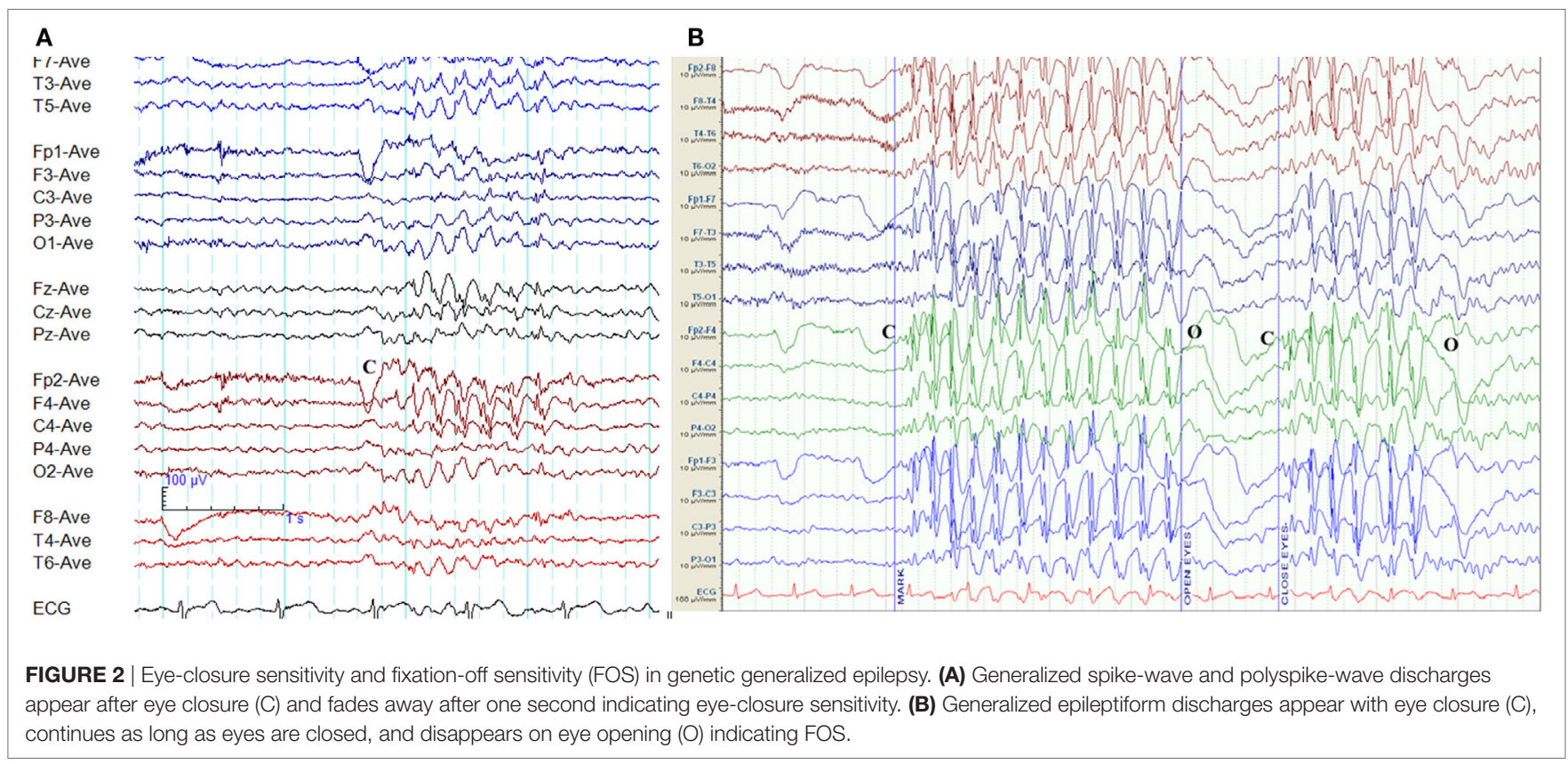




\section{Epileptiform K-Complexes and Sleep Spindles}

The overlap between generalized epileptiform discharges and $\mathrm{K}$-complexes (epileptiform K-complexes) as well as sleep spindles (epileptiform sleep spindles) has been known to researchers for many decades $(32,33)$. This overlap generates complexes with a very characteristic morphology and topography (Figure 3) (33). A recent study has found this to be common in GGE with $65 \%$ of patients demonstrating epileptiform K-complexes and 10\% epileptiform sleep spindles (34). These abnormalities probably indicate the link between microarousals and epileptiform discharges in GGE (34).

\section{Occipital Intermittent Rhythmic Delta Activity}

Occipital intermittent rhythmic delta activity is characterized by transient unilateral or bilateral occipital runs of $2-3 \mathrm{~Hz}$, regular, rhythmic, and sinusoidal delta activity (5). Deep stages of sleep, as well as eye opening, typically attenuate OIRDA, whereas drowsiness and hyperventilation make it more prominent (35). It is detected in approximately one-third of patients diagnosed with CAE (36). Though often reported as an EEG abnormality of CAE, OIRDA is not specific to epilepsy. It is occasionally seen in encephalopathies, particularly in children (35).

\section{ICTAL EEG CHANGES}

\section{Myoclonic Seizures}

High-amplitude, generalized, polyspike activity of $10-16 \mathrm{~Hz}$ with the frontocentral maximum is the EEG hallmark of myoclonic seizures $(19,37)$. These typical discharges may be preceded by irregular 2-5 Hz GSW activity and sometimes followed by irregular slow waves of 1-3 Hz (Figure 4) $(19,37,38)$. The EEG seizure may be several seconds longer than the clinical seizure $(37,38)$.

\section{Typical Absence Seizures}

Bilateral, regular, symmetrical, and synchronous 3-Hz spike-wave activity (range 2.5-4 Hz) sometimes admixed with polyspikewave discharges on a normal background is the hallmark of a typical absence seizure (Figure 5) $(39,40)$. There are some differences among syndromes.

It is not unusual for the initial ictal discharge to be atypical. It could be non-generalized, spike-wave, polyspike-wave, or irregular discharges, with typical GSW activity appearing after an average of $0.7 \mathrm{~s} \mathrm{(7).}$

\section{Myoclonic Absence Seizures}

Myoclonic absence seizures are semiologically characterized by absences in association with tonic contractions resulting in progressive upper limb elevation and superimposed rhythmic myoclonic jerks (2). The impairment of awareness is less pronounced in comparison to typical absence seizures. Both myoclonic absence and typical absence seizure have similar ictal EEG patterns (Figure 6) $(2,41)$. Polygraphic recordings are used to demonstrate the correlation between the ictal EEG and tonic as well as myoclonic activity. Often triggered by hyperventilation, myoclonic absence seizures are less frequently (14\%) induced by intermittent photic stimulation (41).

\section{Absence Seizures with Eyelid Myoclonia}

Eyelid myoclonia with absences, EEG paroxysms/seizures triggered by eye closure, and photosensitivity are the main features of Jeavons syndrome (42). Sometimes, eyelid myoclonia may not be associated
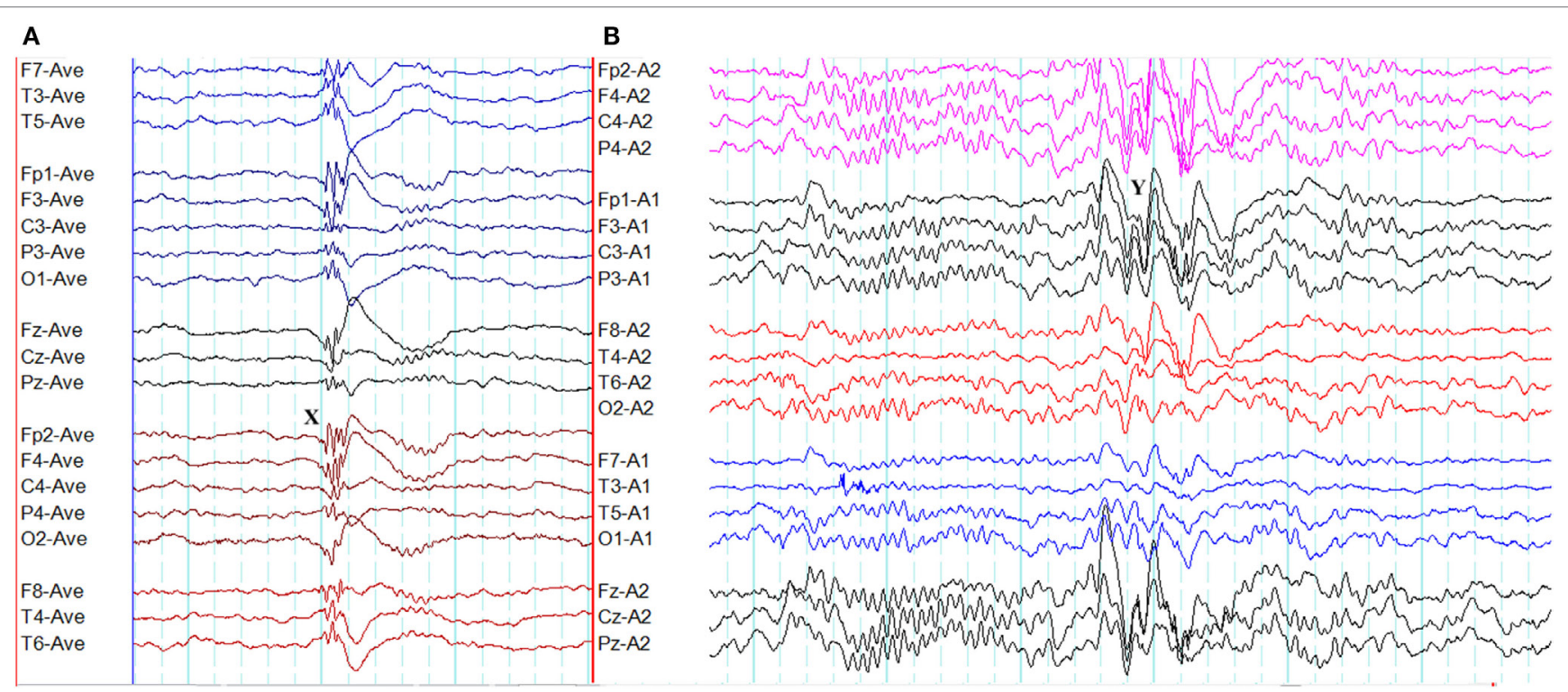

FIGURE 3 | Epileptiform K-complexes and sleep spindles in genetic generalized epilepsy. (A) Polyspikes overlap with a K-complex at X. (B) A burst of generalized spike-wave discharges $(Y)$ in the midst of a sleep spindle. 


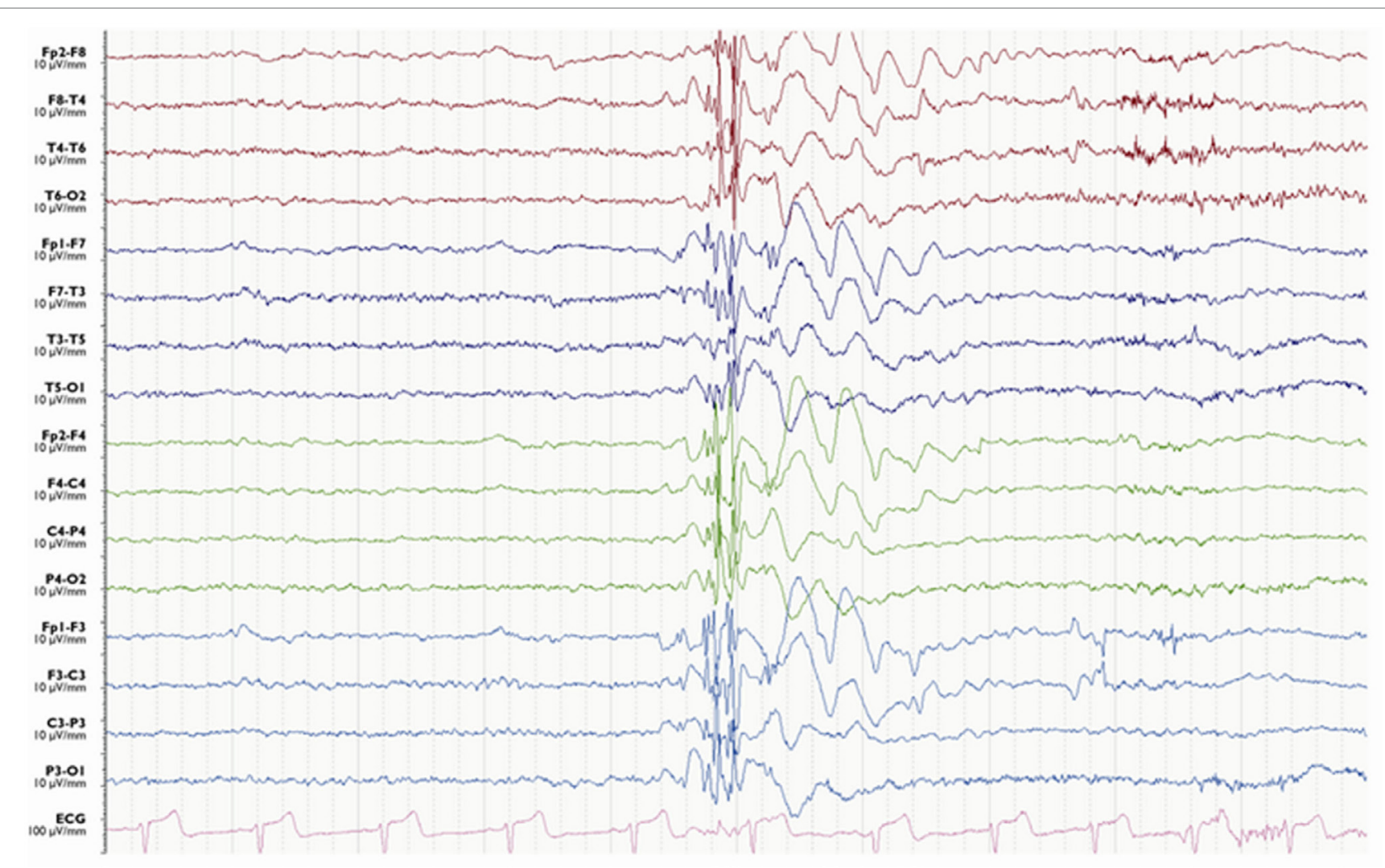

FIGURE 4 | Electroencephalography of a myoclonic seizure. A burst of generalized polyspike-wave activity is followed a few slow waves.

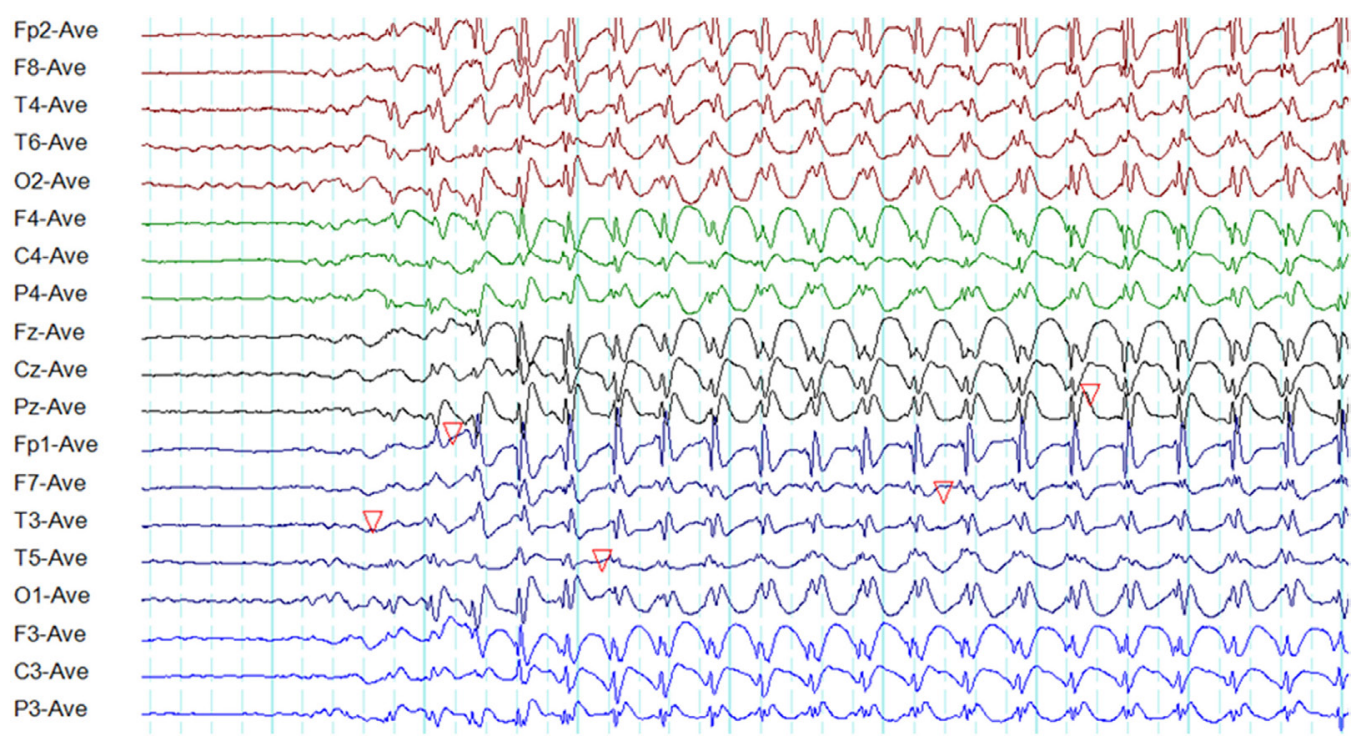

FIGURE 5 | Electroencephalography of a typical absence seizure. Note the paroxysm of generalized, symmetrical, synchronous, and regular 3-Hz spike-wave discharges of frontocentral maxima.

with an absence seizure (42). The ictal EEG typically shows generalized high-amplitude polyspikes and polyspike-wave discharges of 3-6 Hz lasting 1.5-6 s (Figure 7) (42). The ictal discharges occur with or before the onset of eyelid myoclonia (42). The EEG abnormalities are usually triggered by eye closure, intermittent photic stimulation, and hyperventilation (42). FOS may coexist (42). 


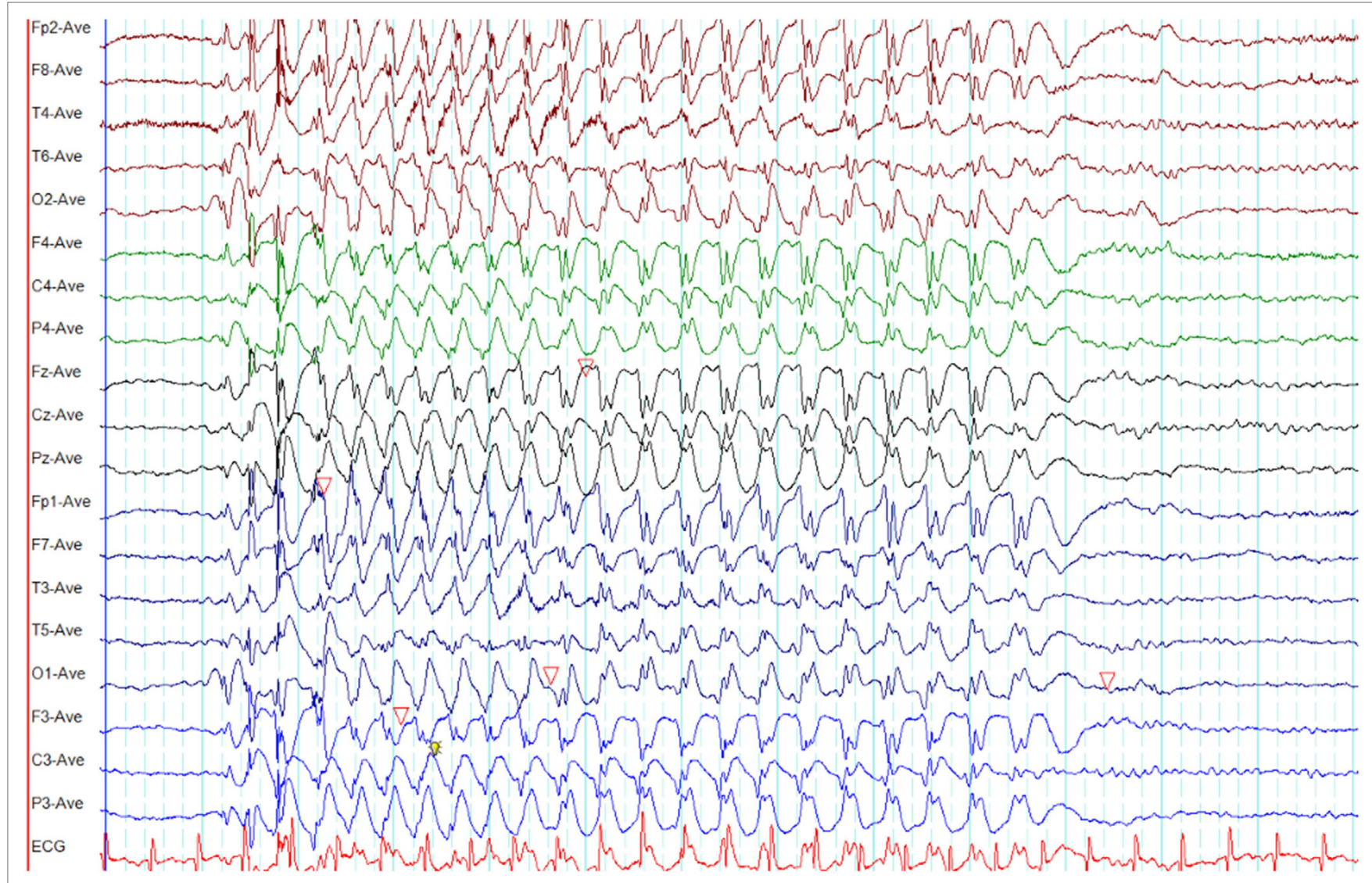

FIGURE 6 | Electroencephalography (EEG) of a myoclonic absence seizure. Note the paroxysm of spike-wave discharges is similar to a typical absence seizure as illustrated in Figure 4 (time-base of this EEG $=20$ s/page).

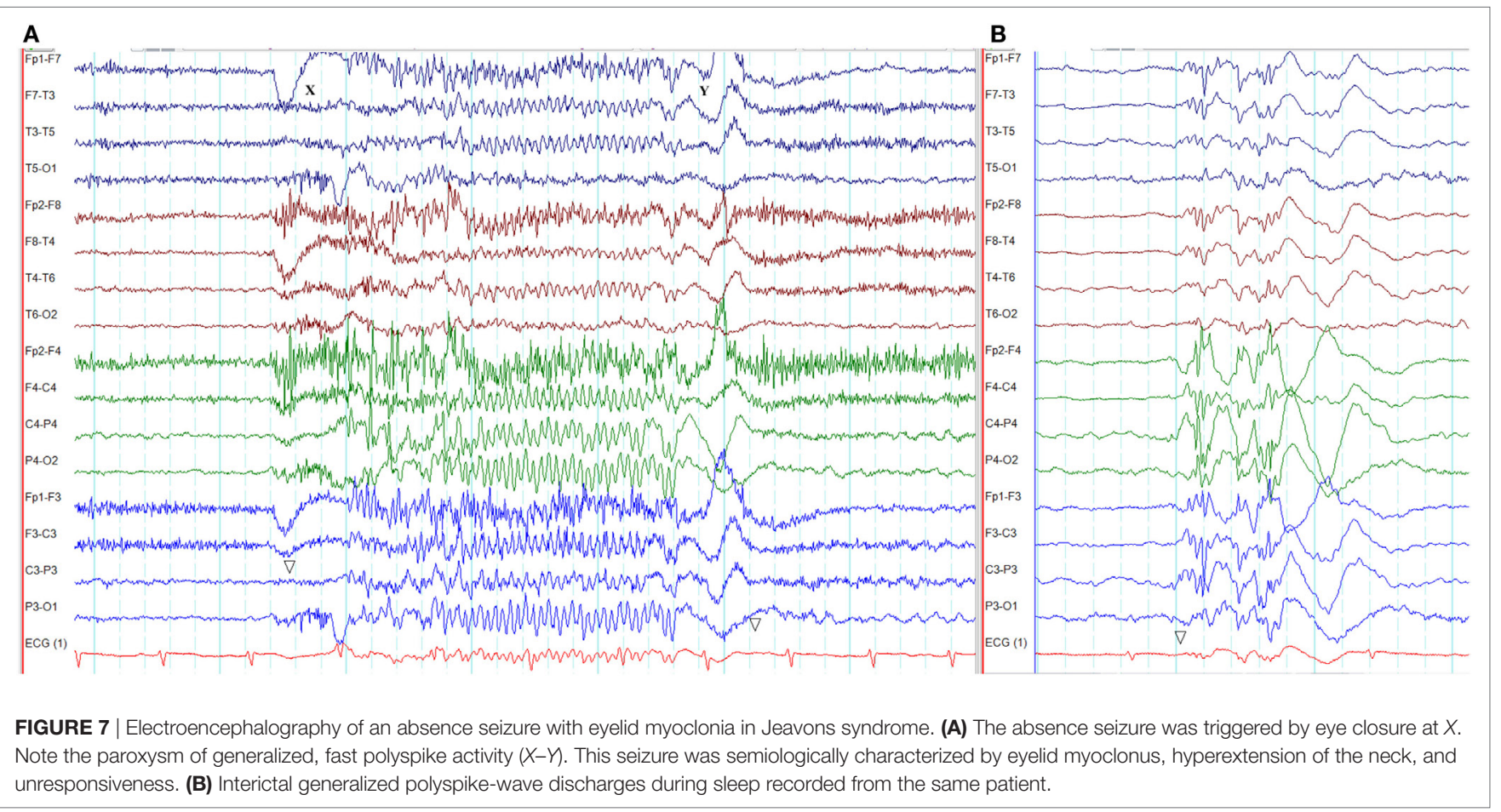




\section{Generalized Tonic-Clonic Seizures}

Muscle and movement artifacts mask the EEG during GTCS unless muscle relaxants are used to paralyze the subject. Generalized polyspike-wave bursts usually mark the ictal onset. Generalized amplitude attenuation follows, with or without low voltage, generalized, $20-40 \mathrm{~Hz}$ fast activity superimposing for a few seconds. The onset of the tonic phase coincides with the voltage attenuation. Then, generalized rhythmic alpha activity $(10-12 \mathrm{~Hz})$ evolves with increasing amplitude and decreasing frequency accompanied by the ongoing tonic phase. When the decreasing frequency reaches $4 \mathrm{~Hz}$, repetitive polyspike-wave complexes emerge accompanied by myoclonic and clonic jerking semiologically. With the progression of the seizure, periodic bursts of polyspike-wave discharges appear with background suppression in between. Generalized EEG suppression is seen for a variable period with the termination of clonic jerking. The gradual recovery is marked by the restoration of the background rhythm from irregular generalized delta slowing proceeding to theta, and finally alpha rhythm (38).

\section{ATYPICAL EEG ABNORMALITIES}

The typical EEG abnormalities in GGE are generalized, symmetrical, and bisynchronous epileptiform discharges. However, for many decades, atypical EEG abnormalities such as focal discharges, lateralized discharges, asymmetries, and irregular discharges have been reported in the literature (43-47). In absence seizures, the initial discharge has been found to be nongeneralized in 50\% (36).

A recent study based on 24-h ambulatory EEGs has quantified theatypicalepileptiformEEGabnormalitiesinGGE(48). Thisstudy identified six atypical EEG abnormalities: (1) amplitude asymmetry, (2) focal onset of paroxysms, (3) focal offset of paroxysms,
(4) focal epileptiform discharges, (5) abnormal morphology, and (6) generalized paroxysmal fast rhythm (Figures 8-12). It was found that $66 \%$ of GGE patients had at least one type of atypical abnormality in the 24-h EEG recording. Patients diagnosed with JAE and JME had those abnormalities most frequently, followed by epilepsy with generalized tonic-clonic seizures alone (GTCSA) and CAE. The most frequent atypical abnormality in the cohort was atypical morphology in $93.4 \%$ of patients. Other atypical EEG abnormalities were amplitude asymmetry (28\%), focal discharges (21.5\%), focal onset (13.1\%), focal offset (8.2\%), and generalized paroxysmal fast rhythm (1.9\%) (48). It is of practical relevance to note that atypical abnormalities may result in misdiagnosis and delayed diagnosis (47).

\section{PROVOKING FACTORS AFFECTING THE EEG}

\section{Arousals, Sleep, Sleep Deprivation, and Circadian Rhythmicity}

There are circadian variations in seizures and epileptiform discharges in GGE. Generalized spike-wave (GSW) activity is seen more often in non-rapid eye movement (NREM) sleep, but rare in rapid eye movement sleep (49). In GGE, sleep deprivation significantly increases the density of spike-wave discharges in both sleep and wakefulness (50). In JME, routine EEGs (without sleep deprivation) done in the morning are more often abnormal than those done in the afternoon (51). In JME, sleep EEG always shows epileptiform discharges (52).

Epileptiform discharges in GGE appear to be closely related to sleep-wake cycle. A retrospective study based on 24-h ambulatory EEGs found that $4.6 \%$ of patients had epileptiform discharges correlating with awakening. All patients who had epileptiform
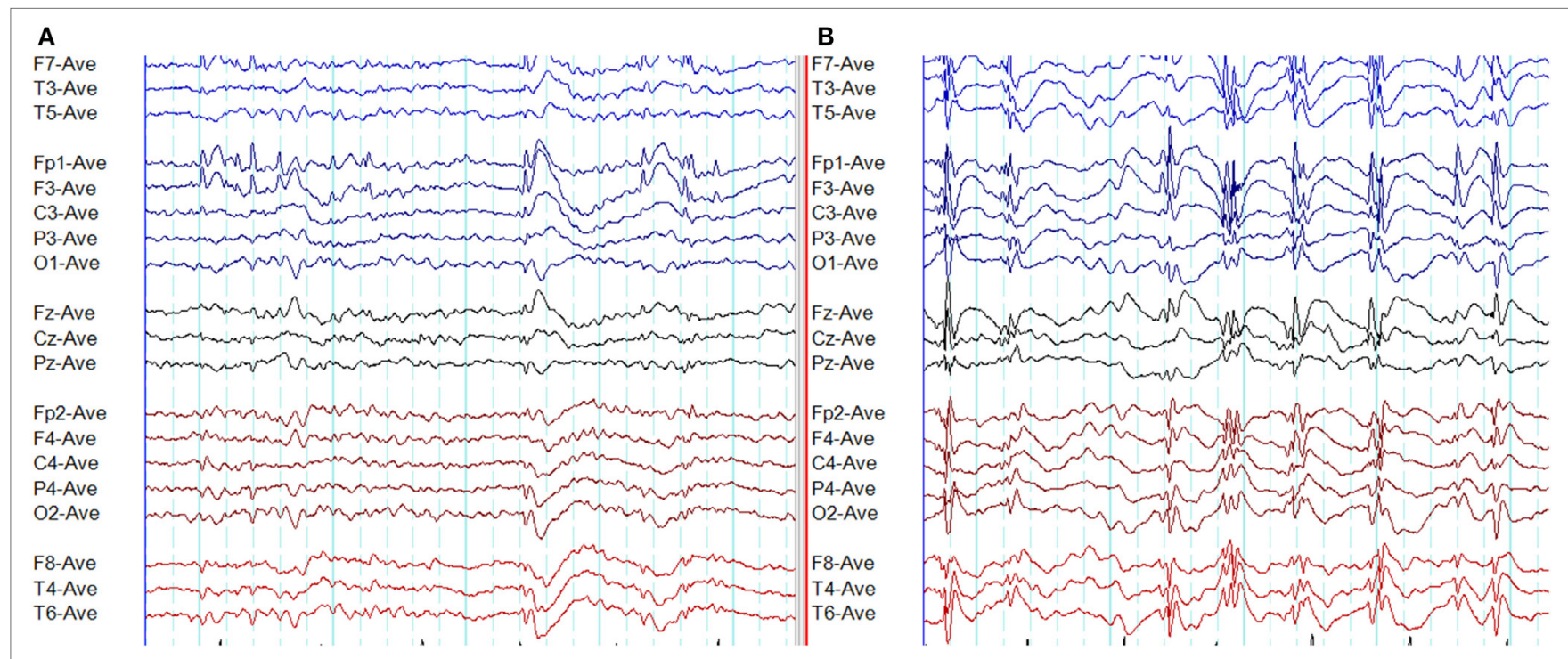

FIGURE 8 | Atypical epileptiform discharges: amplitude asymmetry. (A) Note asymmetric epileptiform discharges with higher amplitude in the left frontal region. Synchronous epileptiform discharges of low amplitude are evident on the right on careful inspection. (B) More symmetric generalized epileptiform discharges recorded from the same patient. 


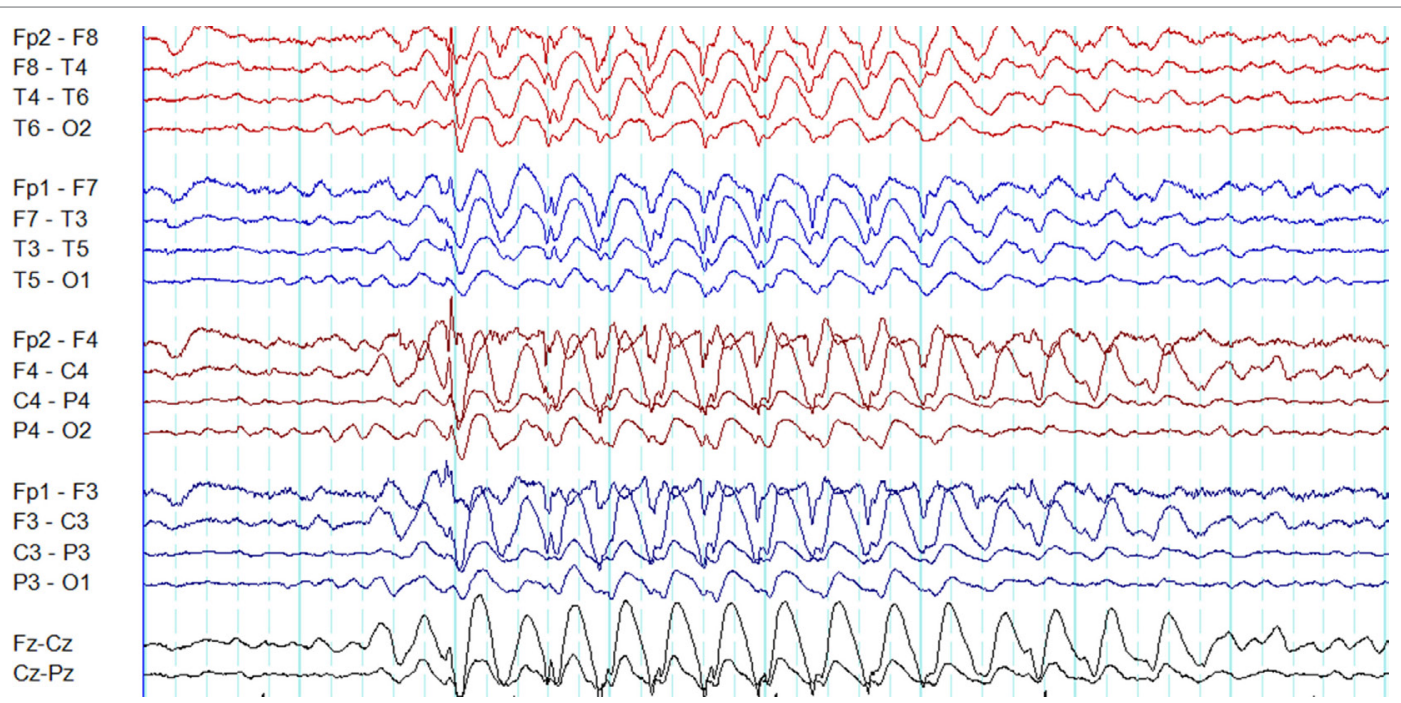

FIGURE 9 | Atypical epileptiform discharges: focal onset and offset of paroxysms. A generalized spike-wave paroxysm in juvenile absence epilepsy. Note the focal onset and offset in the left frontal region.
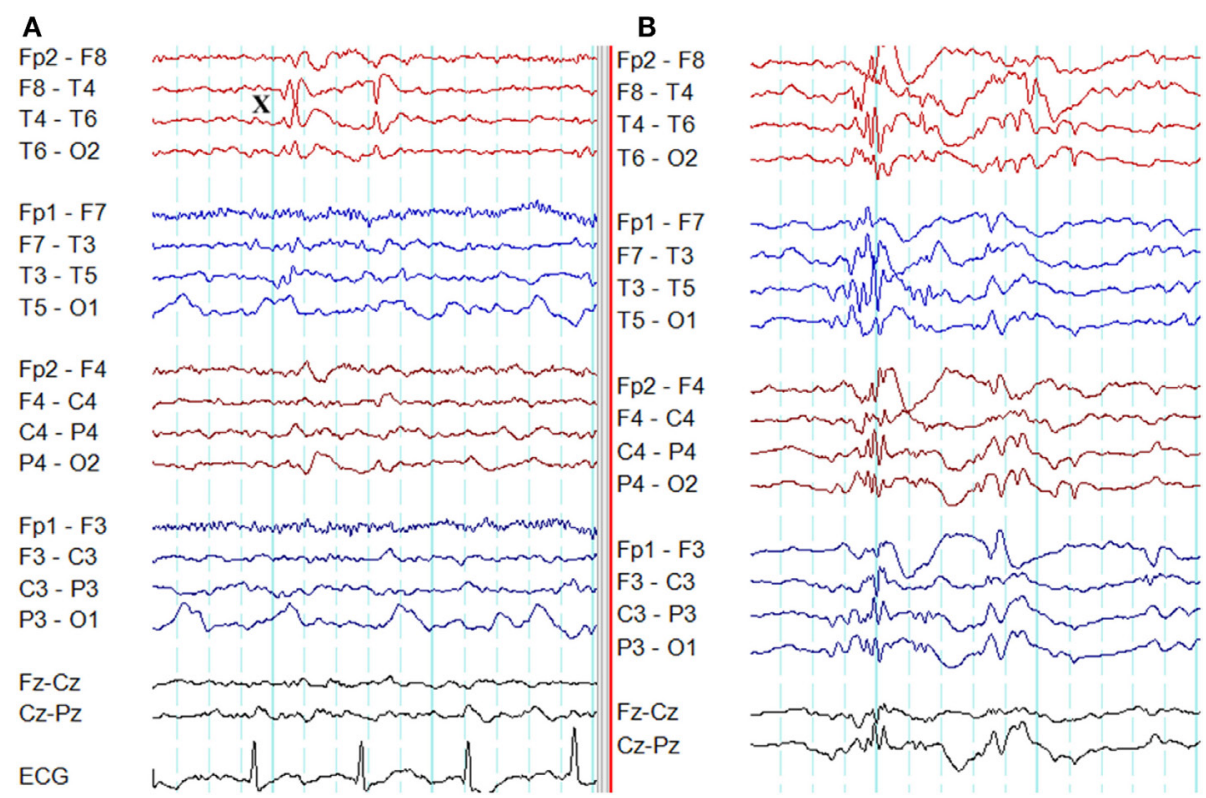

FIGURE 10 | Atypical epileptiform discharges: focal discharges. (A) Note focal discharges at right temporal region (X). (B) Generalized epileptiform discharges recorded from the same patient.

discharges on awakening were diagnosed with GGE. The epileptiform discharges were detected between 20 and $50 \mathrm{~min}$ following awakening in JME (53).

The interaction between circadian rhythmicity and the sleepwake cycle in the generation of epileptiform discharges in GGE has been evaluated in a recent study (54). Epileptiform discharges are significantly shorter in duration and more frequent during the NREM sleep compared with wakefulness. When quantified, $67 \%$ of epileptiform discharges are detected in NREM sleep whereas
$33 \%$ occurs in wakefulness. The distribution of epileptiform discharges demonstrates two peaks ( 11 p.m. to 7 a.m. and 12 noon to 4 p.m.) and two troughs ( 6 p.m. to 8 p.m. and 9 a.m. to 11 a.m.) (54). These findings highlight the variability in the diagnostic yield in relation to the time-of-day and sleep-wake cycle. The best time for the optimal yield of EEG abnormalities is from 11 p.m. to 7 a.m. Similarly, capturing natural sleep during the EEG recording significantly increases the diagnostic yield (54). Hence, 24-h ambulatory EEG is a very useful diagnostic tool in GGE. 


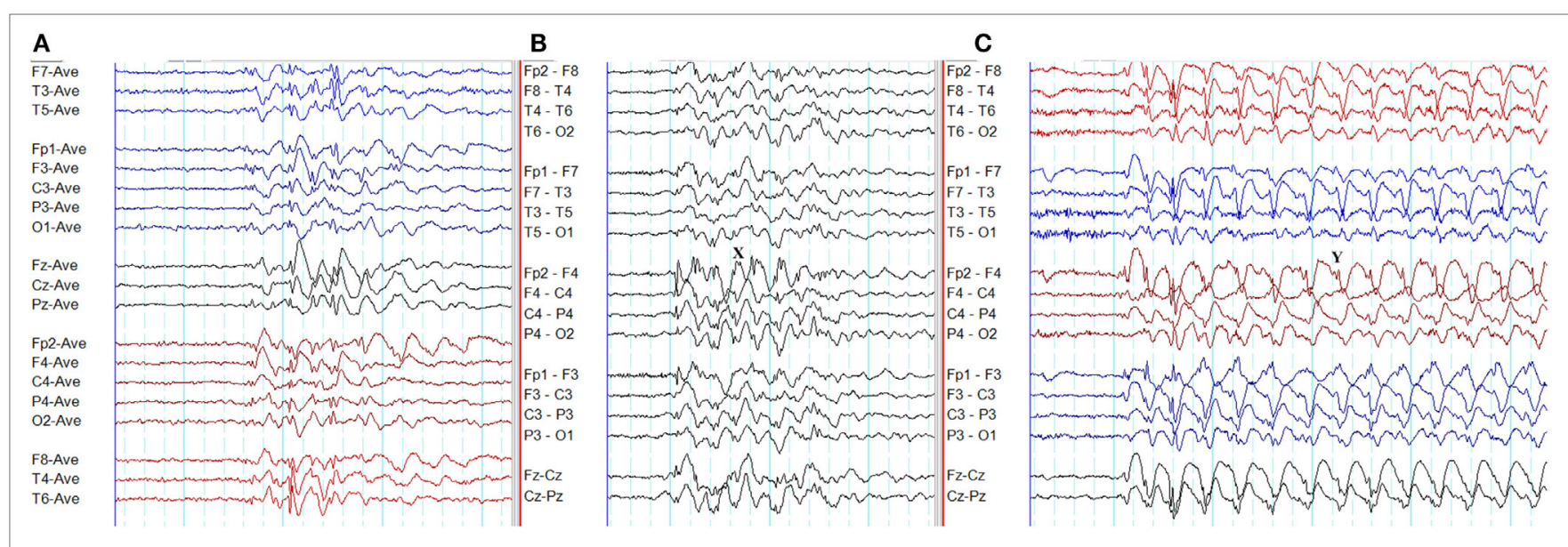

FIGURE 11 | Atypical epileptiform discharges: abnormal morphology. (A) Waves without spikes. Note at the end of spike-wave paroxysms there are waves without preceding spikes. (B) Spikes overriding the waves. Note spikes on top of the wave at $X$. (C) Spikes overriding the waves. Note spikes on the descending limb of the preceding wave $(Y)$.
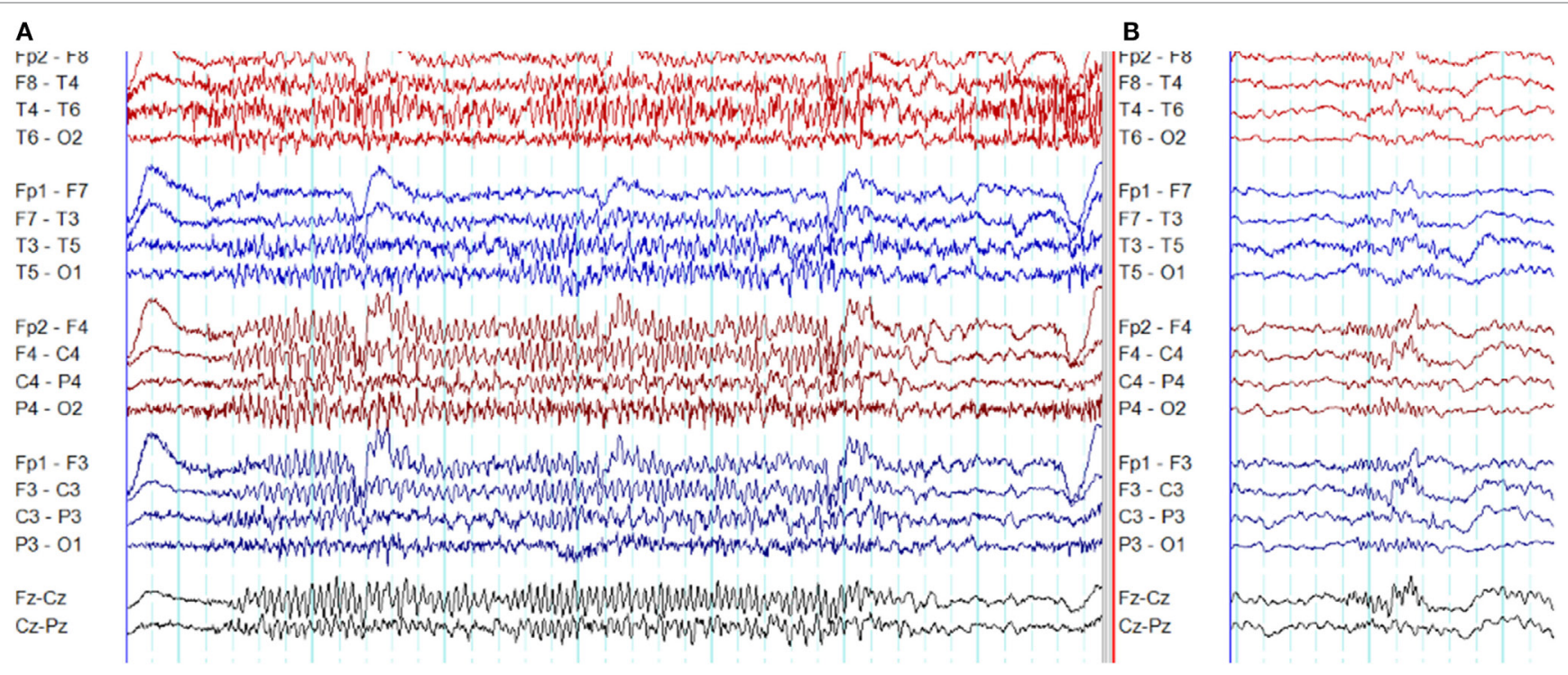

FIGURE 12 | Atypical epileptiform discharges: generalized paroxysmal fast rhythm. (A) A run of generalized fast activity in wakefulness. (B) Similar changes during sleep.

\section{Hyperventilation}

Hyperventilation is routinely used as an activation method in EEG. Hyperventilation-induced EEG abnormalities seem to depend on the severity of hypocapnia and the reduction in cerebral blood flow (55).

Hyperventilation often induces ictal and interictal abnormalities in children diagnosed with absence seizures (56). Hyperventilation triggered absence seizures in $67 \%$ of patients in a pediatric cohort (mean age 9.3 years) diagnosed with JAE and CAE (55). In untreated children, hyperventilation induces absence seizures more often in CAE and JAE (87\% each) in comparison to JME (33\%) (7). In contrast, another study involving a predominantly adult cohort, during hyperventilation, no one with generalized epilepsy had seizures and only $12.2 \%$ had an increase in interictal epileptiform discharges (57). Hyperventilationinduced GSW paroxysms were found in only $12.3 \%$ of adult patients with GGE on treatment (13). These studies suggest that during hyperventilation absence seizures are more likely to occur in the younger age group with untreated CAE and JAE.

\section{Photic Stimulation}

Intermittent photic stimulation is a routine induction technique during EEG recordings. The PPR is more often seen in generalized epilepsy than in focal epilepsy. It is under the influence of several variables including age, sex, antiepileptic drug therapy, level of arousal, sleep deprivation, and the stimulation technique (4). 


\section{Reflex Triggers}

Reflex seizures on exposure to specific stimuli are sometimes encountered in GGE. The use of such stimuli as activating procedures during the EEG recording in selected patients is an option to improve the yield of EEG abnormalities.

Reflex seizures involving visual stimulation have been reported in several epilepsy syndromes including GGE symptomatic generalized epilepsy, and occipital epilepsy (58). Flickering lights, patterns, video games, and television are among the common visual triggers. Both photosensitivity and pattern sensitivity are implicated in television and video game induced seizures. Around $90 \%$ of patients with electrographic pattern sensitivity also demonstrate PPR (59). 3D television and movies do not pose a higher risk of reflex seizures than 2D television and movies (60).

Non-verbal cognitive stimuli such as thinking and praxis may induce reflex seizures in GGE. In a study involving reflex epilepsy triggered by spatial tasks, card or board games, and calculation, 96\% experienced generalized tonic-clonic seizures often preceded by myoclonic jerks, whereas $68 \%$ demonstrated generalized epileptiform discharges on EEG (61). Another study involving 480 patients found that neuropsychological tasks provoked epileptiform discharges in 38 patients and 36 of those patients were diagnosed with GGE (62). Mental arithmetic and decision-making may trigger "noogenic" (thinking-associated) seizures among susceptible individuals. Cognitive activity in conjunction with planned motor tasks usually with hands is implicated in praxis-induced seizures (63). Praxis-induced reflex seizures are particularly common in JME $(45,62)$. Reading, talking, and writing are examples of verbal cognitive stimuli that may trigger reflex seizures. Both generalized and focal epilepsies have been reported under this category (63).

\section{EEG DIFFERENCES AMONG SYNDROMES}

\section{Interictal EEG Abnormalities in Electroclinical Syndromes of GGE}

Several electroclinical syndromes such as CAE, JAE, JME, and epilepsy with generalized epilepsy with tonic-clonic seizures alone (GTCSA) have been described in GGE. In this review, we will focus on the four main syndromes: CAE, JAE, JME, and GTCSA. It should be noted that apart from the electroclinical syndrome, epileptiform abnormalities in GGE are under the influence of many variables including sex, age, the state of alertness, activation procedures, techniques of EEG recording, and antiepileptic drug therapy (4).

\section{Interictal EEG in CAE}

Childhood absence epilepsy is typically seen in children and the EEG signature is "generalized, bisynchronous, and symmetrical $3-\mathrm{Hz}$ spike-wave discharges emerging from a normal background" (2). Fragments of GSW discharges are seen in $>90 \%$ of cases, predominantly in drowsiness and sleep (7). Interictal polyspikes usually occur in drowsiness and sleep (7). Polyspikewave discharges were detected in $26 \%$ of patients in a different series (64). Among untreated children with CAE, only $21 \%$ demonstrate PPR, whereas hyperventilation-induced absence seizures are seen in $87 \%(7)$.
Occipital intermittent rhythmic delta activity is seen in $20-30 \%$ of CAE subjects $(8,36)$, and $40 \%$ of those have a notched appearance (36).

\section{Interictal EEG in JAE}

The onset of JAE is in teenage years (12-17 years). Absence seizures are less frequent but myoclonus is more common in JAE compared with CAE. In comparison to CAE, generalized tonic-clonic seizures more frequently precede the onset absence seizures in JAE (2). Fragmented discharges and polyspikes are seen in all patients, mostly in drowsiness and sleep (7).

\section{Interictal EEG in JME}

Patients with JME typically experience their first seizure at puberty (12-18 years). The typical semiologic feature is myoclonic seizures predominantly involving arms. Generalized tonic-clonic seizures occur more frequently than absences (2). Sleep deprivation and alcohol are potent seizure triggers. Seizures, particularly myoclonus, frequently occur after awakening from sleep (19).

The classic EEG abnormalities in JME are generalized polyspikes and polyspike-wave discharges $(19,38)$. The interictal EEG is characterized by 3-6 Hz spike and polyspike-wave discharges in an irregular mix (28). Focal EEG abnormalities are common (45). PPR is seen in the majority (7). Both eye-closure sensitivity and FOS have been reported in JME (45).

\section{Interictal EEG in GTCSA}

This condition is characterized by GTCS occurring on awakening or at random times. The median age of onset is (18 years) significantly older than JME and JAE (65). The interictal EEG demonstrates generalized polyspikes, polyspike-waves, and spike-wave discharges similar to other GGE syndromes. The mean spike-wave frequency is $3.6 \mathrm{~Hz}$. The density of epileptiform discharges is significantly lower than CAE, JAE, and JME (66).

\section{CHARACTERISTICS OF ABSENCE SEIZURES IN GGE SYNDROMES}

\section{Frequency of GSW Discharges}

In all GGE syndromes, the initial frequency of GSW activity is faster. In the next phase, the discharges become more regular and slower in frequency by $0.4-0.6 \mathrm{~Hz}$. The frequency decreases again in the terminal phase of CAE and JAE (20). The highest median frequency of GSW during the first second of an absence seizure is in JME $(3.5 \mathrm{~Hz})$. It is marginally slower in JAE $(3.25 \mathrm{~Hz})$ and CAE $(3 \mathrm{~Hz})(7)$. In JME, the GSW activity often tends to be faster $(>3.5 \mathrm{~Hz})(19,38,67)$. A more recent study based on 24 -h EEGs found median GSW frequencies of 3.3 (CAE), 3.1 (JAE), 3.8 (JME), and 3.5 (GTCSA). But the differences were not statistically significant (66).

\section{Epileptiform Discharge Morphology and Duration}

Childhood absence epilepsy and JAE demonstrate similar morphologies of GSW discharges. Multiple spikes preceding or overlapping slow waves give rise to an appearance of compressed "W"s in absence seizures of JME (20). The polyspike-wave activity 
is seen more often in JME and JAE than CAE (7). CAE and JAE have longer EEG seizure durations than $\operatorname{JME}(20,68)$. The longest EEG absence seizure is seen in JAE, whereas the shortest is in GTCSA (66).

\section{Organization of Discharges}

Absence seizures typically demonstrate well organized regular and rhythmic ictal EEG pattern. In disorganized discharges, regular rhythmic activity is interrupted by, (a) brief $(<1 \mathrm{~s})$ and transient interruptions in ictal rhythm, or (b) waveforms of different frequency and/or morphology (Figure 13) (7). Disorganized ictal discharges are 110 times more likely to occur in JME than CAE and eight times more likely in JAE than CAE (7). It is also influenced by provoking techniques, the state of arousal, and the age (7). Irregular and disorganized paroxysms are also seen in GTCSA though less frequently (66).

Table 1 summarizes key EEG differences among the four main GGE syndromes.

\section{UNDERPINNING NETWORK MECHANISMS OF GSW COMPLEX}

Currently, epilepsy is considered to be a disorder of network pathways. This concept is reflected in the current International League against Epilepsy terminology defining generalized seizures as those involving both cortical and subcortical bilateral networks (1). Hence, in GGE, the seizure activity originates at a certain point within the epileptic network and then rapidly engages bilaterally distributed network pathways (1).

Many animal and human experiments highlight the importance of frontal lobe and thalamus in the formation and propagation of GSW complexes. In the rat model, absence seizures originate from the somatosensory cortex rapidly spreading to the thalamus (69). In their pioneering work, Bancaud et al. recorded GSW discharges with the mesial frontal cortex stimulation (70). More recently, novel EEG techniques have provided intriguing insights into the underpinning epileptic network pathways in GGE.

\section{Dense Array EEG and Source Localization}

A study based on dense array EEG in absence seizures has demonstrated spike-wave discharge onset in the dorsolateral frontal and orbital frontal regions followed by rapid and stereotypic propagation (71). Electrical source analysis of dense array EEG data has revealed frontotemporal networks involving the slow wave and spike propagation through ventromedial frontal networks during absence seizures (72).

\section{Magnetoencephalography (MEG)/EEG}

A combined MEG/EEG study has described a prefrontal-insular-thalamic network in absence epilepsy (73). In JAE, the spikewave discharge onset is in focal cortical regions with subsequent involvement of the default mode network as demonstrated by synchronous MEG/EEG data (74).

\section{Simultaneous EEG and Functional MRI (EEG-fMRI) Studies}

Electroencephalographic and functional MRI is a non-invasive technique to measure regional brain activation during epileptiform discharges using blood oxygenation level-dependent contrast (75). A recent critical review has elicited three key features among EEG-fMRI findings in GGE: (a) activation of the

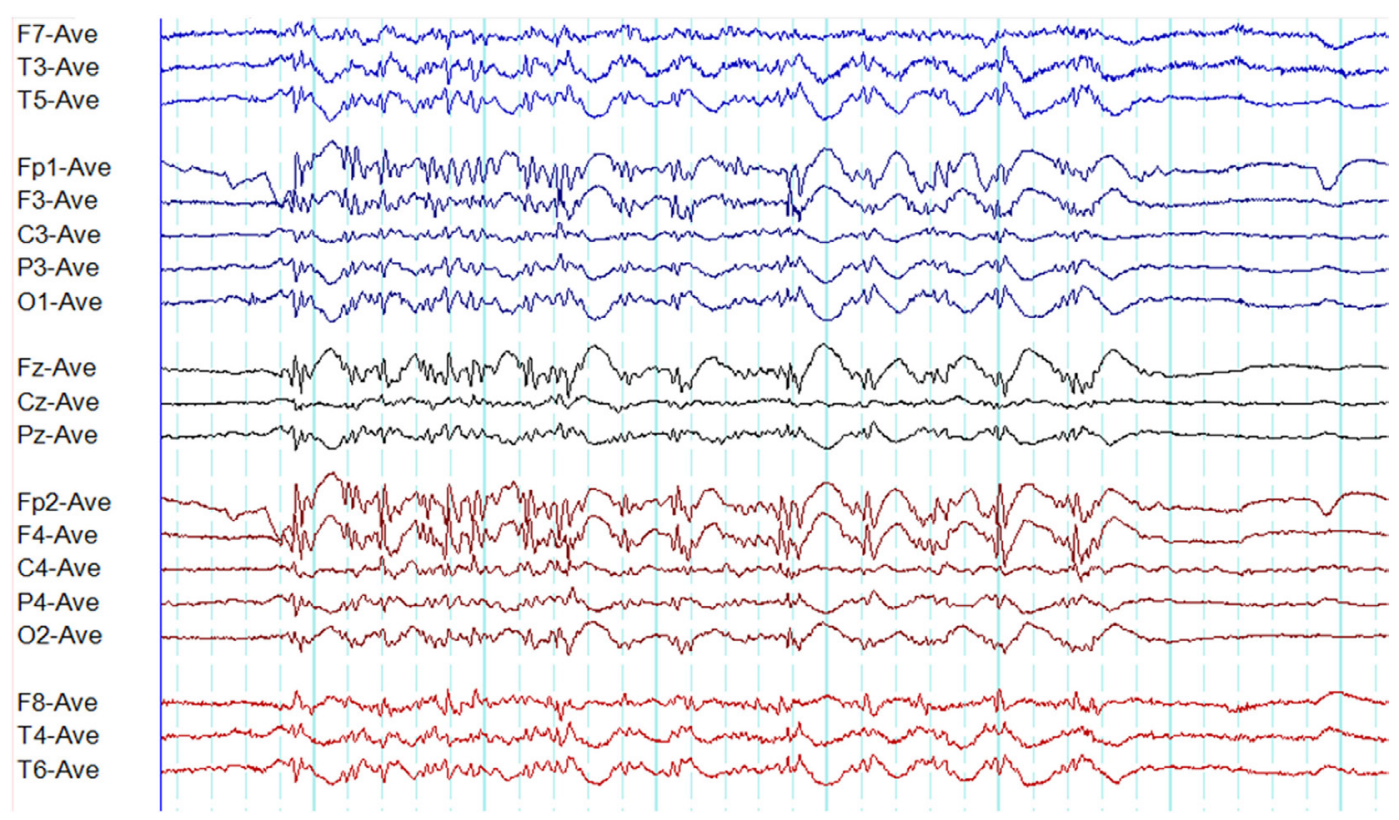

FIGURE 13 | A disorganized (irregular) paroxysm of generalized epileptiform discharges in juvenile myoclonic epilepsy. Note this paroxysm has a mix of polyspikes and polyspike-wave discharges with varying frequency and morphology. 
TABLE 1 | Differences in electroencephalographic (EEG) features among syndromes.

\begin{tabular}{|c|c|c|c|c|c|}
\hline & Reference & CAE & JAE & JME & GTCSA \\
\hline GSWD frequency $(\mathrm{Hz})$ & $(66)$ & 3.3 & 3.2 & 3.9 & 3.6 \\
\hline Irregular and disorganized paroxysms & $(7)$ & Least common & 8 times more likely than CAE & 110 times more likely than CAE & NA \\
\hline $\begin{array}{l}\text { Percentage of GSWD fragments } \\
\text { containing polyspikes }\end{array}$ & (7) & $A-0, D-13 \%, S-40 \%$ & $A-0, D-12 \%, S-24 \%$ & $A-50 \%, D-50 \%, S-50 \%$ & NA \\
\hline Photoparoxysmal response & (7) & $21 \%$ & $25 \%$ & $83 \%$ & NA \\
\hline Absence seizures during hyperventilation & (7) & $87 \%$ & $87 \%$ & $33 \%$ & NA \\
\hline Mean duration of paroxysms (s) & $(66)$ & 2.8 & 4.6 & 3.2 & 2.5 \\
\hline Total spike density & $(66)$ & + & +++ & +++ & + \\
\hline Density of generalized paroxysms & $(66)$ & + & +++ & + & + \\
\hline $\begin{array}{l}\text { Density of polyspikes and polyspike-wave } \\
\text { discharges }\end{array}$ & (66) & + & +++ & ++ & + \\
\hline Density of pure GSWD & (66) & ++ & ++ & + & + \\
\hline
\end{tabular}

CAE, childhood absence epilepsy; GSWD, generalized spike-wave discharges; GTCSA, generalized tonic-clonic seizures alone; JAE, juvenile absence epilepsy; JME, juvenile myoclonic epilepsy; NA, not available; A, awake; D, drowsy; S, sleep; density; duration of epileptiform discharges (in seconds) per an hour of EEG recording; +++, highest value; +, lowest value; +++, middle value; pure GSWD, fragments and paroxysms containing only spike-wave discharges (without any polyspikes or polyspike-wave discharges) (7, 66).

thalamus, (b) activation of cortical regions, particularly frontal, and (c) deactivation of default mode areas (47).

\section{Combined Transcranial Magnetic Stimulation (TMS) and EEG Studies}

Combined TMS and EEG is an emerging non-invasive technique with a potential to study the functional connectivity of the brain (76). A protocol to study GGE patients with TMS-EEG has been recently described (77). However, to date, changes in network connectivity have mostly been studied with TMS-EEG in focal epilepsy (78), while evaluation in GGE remaining in its infancy (79).

\section{Graph Theory and EEG}

Graph theory is a mathematical concept to study brain connectivity. It describes networks in terms of interrelationship between nodes (brain regions) and edges (connections) (80). Graph theory is increasingly being used as a tool to analyze epileptic networks. A recent study has reported increased local connectivity in the frontal regions with spike-wave discharges in JME (81). Another study based on graph theory using EEG data found similarities in network topology between patient with GGE and their unaffected relatives (82).

Conclusions should be drawn with care from these studies due to various limitations. There is wide variability in the methodology among studies. In particular, EEG-fMRI studies vary in terms of study paradigms, and methods of data acquisition as well as analysis. Additionally, most studies are based on GSW activity. In GGE, there are other EEG abnormalities and underpinning network mechanisms may be different in those. Despite such limitations, there is growing support for the hypothesis that spike-wave discharges originate from a cortical focus with rapid spread to the thalamus followed by entrainment of the corticothalamo-cortical loop resulting in the classic GSW activity observed in GGE (83).

\section{DIAGNOSTIC TOOLS}

Routine outpatient EEG, sleep-deprived outpatient EEG, shortterm outpatient video-EEG, inpatient video-EEG, and 24-h ambulatory EEG are common tools used to diagnose and classify epilepsy in routine clinical practice. The yield is influenced by several variables such as age, AED therapy, pretest probability of epilepsy, provoking techniques used, the length of the recording, and the state of arousal (4).

The yield of interictal epileptiform discharges in the routine outpatient EEG is around 28\% (84). After the first seizure, the average yield is $29 \%$ according to a systematic review (85). Serial EEGs appear to increase the diagnostic yield (86). One study based on outpatient short-term video-EEG found the yield to be $17.2 \%$ (87). However, in this study, $22 \%$ of patients had the test with the clinical diagnosis of psychogenic non-epileptic seizures reducing the yield of epileptiform discharges. Inpatient videoEEG monitoring has a higher yield (epileptic seizures $43.5 \%$; interictal epileptiform discharges $43 \%$ ) (88), but is an expensive test with limited availability.

Sleep EEG can be considered the most effective diagnostic tool as $67 \%$ of generalized epileptiform discharges occur in NREM sleep (54). Sleep deprivation appears to increase this yield further. Following sleep deprivation, GSW discharge densities increase in both sleep and wakefulness with the highest densities recorded in NREM sleep stages 1 and 2 (50). Though results in the literature are variable, sleep deprivation appears to increase the yield of epileptiform discharges (focal and generalized) by about $30 \%$ beyond the effect of sleep (89).

The use of multiple provoking techniques increases the diagnostic yield of EEG. A recent study reported a video-EEG protocol incorporating several provoking methods such as sleep deprivation, neuropsychological activation (language and praxis), hyperventilation, eye closure, intermittent photic stimulation, sleep, and arousal (90). The video-EEG was recorded for 4-6 h. Interictal epileptiform discharges were detected in $85.8 \%$ of patients, whereas $54.9 \%$ had seizures during the recording (90). The high yield might have been influenced by the fact that all patients in the cohort had an established diagnosis of GGE. Yet, this study demonstrates the importance of combining multiple provoking techniques to enhance the diagnostic yield.

Recent research indicates 24 -ambulatory EEG to be a very useful test to diagnose and classify GGE (54). Its diagnostic sensitivity 
is 2.23 times higher than routine EEG (91). Ambulatory EEG recordings are very effective for several reasons. First, two-thirds of epileptiform discharges appear on sleep EEG recording and ambulatory EEG the most practical method to capture the natural sleep and increase the diagnostic yield (54). Second, epileptiform discharges in GGE demonstrates a time-of-day dependence with two peaks (11 p.m. to 7 a.m. and 12 noon to 4 p.m.) and two troughs (6 p.m. to 8 p.m. and 9 a.m. to 11 a.m.) (54). Routine outpatient EEG is likely to miss the most significant first peak (11 p.m. to 7 a.m.) while the 24-h ambulatory will capture both peaks. Third, it is four times cheaper than inpatient video-EEG (92). Finally, home-based ambulatory EEG is more convenient and acceptable to patients than hospital-based inpatient monitoring (93).

\section{DIAGNOSTIC PITFALLS}

\section{Misdiagnosis of People without Epilepsy As Generalized Epilepsy}

Paroxysmal disorders ranging from syncope to psychogenic non-epileptic seizures can be misdiagnosed as epilepsy. The rate of misdiagnosis is as high as $20-30 \%$ in general practice and outpatient clinics $(94,95)$. Misdiagnosis is likely to happen when an individual presenting with a non-epileptic disorder undergoes an EEG test yielding epileptiform abnormalities. It has been shown that $0.5 \%$ of healthy adults in the general population have epileptiform abnormalities in the EEG (25). Among healthy school children, the prevalence of GSW activity in the EEG is 0.9\% (96). Epileptiform discharges are more frequently (37\%) detected among the offspring of patients with epilepsy. $6 \%$ of healthy firstdegree relatives of JME probands demonstrate typical generalized epileptiform discharges $(97,98)$. Hence, we wish to emphasize the importance of clinical correlation of EEG abnormalities in establishing the diagnosis of epilepsy.

\section{Misdiagnosis of Generalized Epilepsy As Focal Epilepsy}

Atypical features, including focal epileptiform discharges, can potentially result in delayed diagnosis and misdiagnosis of GGE. The rate of misdiagnosis can be as high as $91 \%$ and the mean delay to the diagnosis ranges from 6 to 15 years in studies (47). As a result, many patients receive inappropriate antiepileptic drugs such as carbamazepine leading to paradoxical worsening of some seizures (47).

\section{Misdiagnosis of Focal Epilepsy As Generalized Epilepsy Secondary Bilateral Synchrony}

Tukel and Jasper coined the term "secondary bilateral synchrony" while reporting a series of patients with parasagittal lesions in whom the EEGs demonstrated bilaterally synchronous bursts of spike-wave complexes (99). Along with Penfield, they postulated that "a cortical focus can fire into subcortical structures and set off a projected secondary bilateral synchrony" (99). Subsequently, a stereo-EEG study reported that stimulation of the mesial frontal region induced paroxysms of bilaterally synchronous and symmetrical spike-wave discharges (70).
Blume and Pillay proposed three diagnostic criteria for secondary bilateral synchrony; (1) $\geq 2$ s of lead-in time, (2) focal triggering spikes having a different morphology from the bisynchronous discharges, and (3) both triggering spikes and focal spikes from the same region having similar morphology (100). This is a rare phenomenon occurring in $0.5 \%$ of patients undergoing EEGs and is most frequently seen in association with frontal lobe foci (100).

\section{Frontal Lobe Epilepsy: The Conundrum of "Pseudo Bilateral Synchrony"}

In frontal lobe epilepsy, the interictal epileptiform abnormalities range from focal to bilateral synchronous discharges. In a surgical series of frontal lobe epilepsy, $9 \%$ had bifrontal independent interictal epileptiform discharges whereas bilaterally synchronous discharges were recorded from $37 \%$ of patients (101). Epileptiform discharges recorded on the scalp EEG represent the summated activity of volume conduction and cortico-cortical propagation. Cortico-cortical propagation gives rise to asynchronous discharges with a time a lag. However, small time lags may not be appreciated by visual inspection and can be interpreted as synchronous discharges $(102,103)$. Hence, it is conceivable that frontal foci, particularly located in the midline, can generate bifrontal epileptiform discharges with "pseudo bilateral synchrony" that can be mistaken for truly bisynchronous discharges of GGE. Computer-aided analysis (104) or specific re-montaging (reference-subtraction montage) (103) can be used to detect the time lag between the electrodes and demonstrate that bilateral discharges are not truly synchronous but generated from a single a focus. Expanding the time-base of digital EEG is also a useful manipulation to detect time differences between seemingly synchronous discharges on two separate channels (Figures 14 and 15) (105).

\section{Misdiagnosis of Normal Variants As Generalized Epileptiform Discharges}

The 6-Hz spike-wave (phantom spike-wave) pattern consists of bursts of generalized symmetric spike-wave discharges with a very low amplitude spike component (106). The bursts are typically very brief but can last up to $4 \mathrm{~s}$ on rare occasions (106). The amplitude maxima can be anterior or posterior (107). This variant, particularly the type with posterior maximum, usually emerges from drowsiness and disappears during deep sleep. Though the typical frequency is $6 \mathrm{~Hz}$, it can range from 4 to $7.5 \mathrm{~Hz}$ (107). The spike component is $<25 \mu \mathrm{V}$ in the majority and $>75 \mu \mathrm{V}$ in $5 \%$ (107). This is a benign variant of no clinical significance.

The 14 - and $6-\mathrm{Hz}$ positive burst pattern (14 and $6 \mathrm{~Hz}$ positive spikes or ctenoids) is a benign variant most often seen in early teens, which then becomes infrequent with advancing age. These spikes are surface positive in polarity, occurring in bursts of $<1 \mathrm{~s}$, with unilateral or bilateral distribution and posterior dominance during drowsiness and light sleep (106). This can be mistaken for polyspikes, but careful analysis of the polarity, frequency, and distribution should help clarify the diagnosis.

Small sharp spikes (benign sporadic sleep spikes) are seen in adults during drowsiness and light sleep. It disappears in deep sleep. The sharp waves are usually diphasic with a low amplitude 


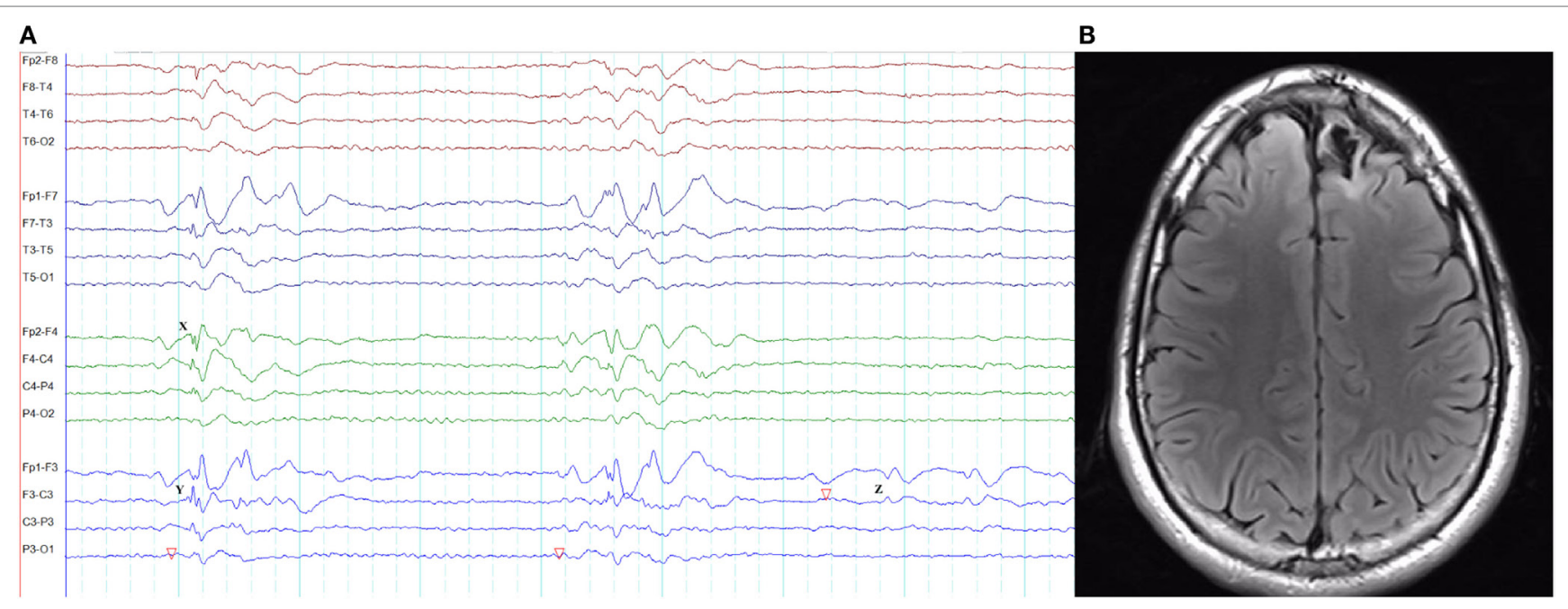

FIGURE 14 | Pseudo bilateral synchrony in frontal lobe epilepsy. This patient presented with seizures following the surgery for left frontal brain abscess in the past. (A) In this longitudinal bipolar montage, bifrontal polyspike-wave discharges $(X, Y)$ appear synchronous. However, focal sharp wave discharges are evident involving F3 electrode at $Z$. (B) The MRI demonstrating left frontal encephalomalacia.

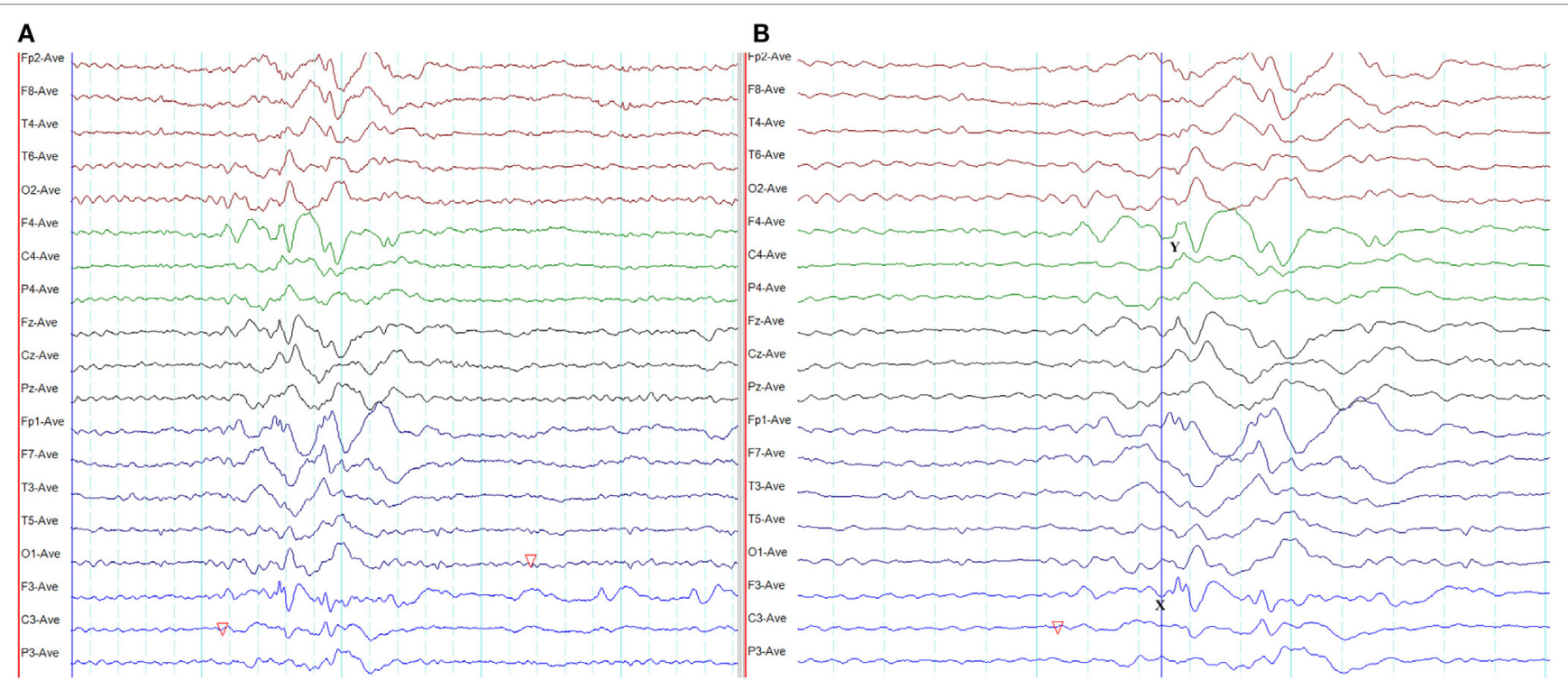

FIGURE 15 | Pseudo bilateral synchrony in frontal lobe epilepsy. (A) This average referential montage demonstrates the same activity seen in (A) of Figure 14. The discharges appear bifrontal. Note focal discharges involving F3 and C3 (time-base of the electroencephalography $=10 \mathrm{~s} /$ page). (B) When the time-base is expanded to $5 \mathrm{~s} /$ page, it becomes clear that the epileptiform discharge emerges first on the left at Fp1 and F3 $(X)$, followed by activity on the right ( $Y$ ) confirming pseudo bilateral synchrony.

$(<50 \mu \mathrm{V})$ and brief duration $(<50 \mathrm{~ms})$ without an after-going slow wave. The spikes occur in the form of isolated transients with a unilateral or bilateral widespread field most prominent in the temporal regions (106).

\section{GAPS IN THE LITERATURE AND FUTURE DIRECTIONS}

Drawing robust conclusions from the literature is challenging due to wide variability in methodology. Additionally,
EEG abnormalities in GGE are influenced by numerous confounding variables affecting the results. Most studies are descriptive in nature limiting the option of drawing statistical conclusions. Finally, most studies are based on short-term EEG recordings.

To circumvent these shortcomings, prospective studies in drug naïve populations with GGE using standardized EEG recording protocols are needed. Longer $(\geq 24 \mathrm{~h})$ EEG monitoring is required to study both circadian and infradian rhythms. Additionally, there is a potential role for long-term EEG monitoring to evaluate 
seizure control and occupational safety including fitness to drive. The application of machine-learning technologies allows more rapid and accurate identification of abnormalities from large volumes of long-term recordings and permits accurate quantification that may provide new insights into classification, prognosis, and clinical outcomes.

More research should focus on the distinction and interrelationship between interictal and ictal epileptiform discharges. From the clinical perspective, more analytical studies are needed to delineate EEG differences among GGE syndromes. Beyond its routine clinical interpretation, EEG data can be used for computational modeling to study network dynamics (108). Research on network analysis in GGE needs to focus on all types of epileptiform abnormalities and associated networks.

\section{CONCLUSION}

As highlighted in this review, there are several typical EEG features of GGE. The occurrence of atypical features, in particular, focal changes, should be borne in mind to avoid misdiagnosis. The use

\section{REFERENCES}

1. Berg AT, Berkovic SF, Brodie MJ, Buchhalter J, Cross JH, van Emde Boas W, et al. Revised terminology and concepts for organization of seizures and epilepsies: report of the ILAE Commission on Classification and Terminology, 2005-2009. Epilepsia (2010) 51(4):676-85. doi:10.1111/j.1528-1167.2010. 02522.x

2. ILAE. Proposal for revised classification of epilepsies and epileptic syndromes. Commission on classification and terminology of the international league against epilepsy. Epilepsia (1989) 30(4):389-99. doi:10.1111/ j.1528-1157.1989.tb05316.x

3. Scheffer IE, Berkovic S, Capovilla G, Connolly MB, French J, Guilhoto L, et al. ILAE classification of the epilepsies: position paper of the ILAE COMMISSION for Classification and Terminology. Epilepsia (2017) 58(4):512-21. doi:10.1111/epi.13709

4. Seneviratne U, Cook M, D'Souza W. The electroencephalogram of idiopathic generalized epilepsy. Epilepsia (2012) 53(2):234-48. doi:10.1111/j.1528-1167.2011.03344.x

5. Chatrian GE, Bergamini L, Dondey M, Klass DW, Lennox-Buchthal M, Petersen I. A glossary of terms most commonly used by clinical electroencephalographers. Electroencephalogr Clin Neurophysiol (1974) 37:538-48. doi:10.1016/0013-4694(74)90099-6

6. Blumenfeld H. Consciousness and epilepsy: why are patients with absence seizures absent? Prog Brain Res (2005) 150:271-86. doi:10.1016/ S0079-6123(05)50020-7

7. Sadleir LG, Scheffer IE, Smith S, Carstensen B, Farrell K, Connolly MB. EEG features of absence seizures in idiopathic generalized epilepsy: impact of syndrome, age, and state. Epilepsia (2009) 50(6):1572-8. doi:10.1111/j.1528-1167.2008.02001.x

8. Dlugos D, Shinnar S, Cnaan A, Hu F, Moshe S, Mizrahi E, et al. Pretreatment EEG in childhood absence epilepsy: associations with attention and treatment outcome. Neurology (2013) 81(2):150-6. doi:10.1212/ WNL.0b013e31829a3373

9. Gibbs FA, Davis H, Lennox WG. The electro-encephalogram in epilepsy and in conditions of impaired consciousness. Arch Neurol Psychiatry (1935) 34:1133-48. doi:10.1001/archneurpsyc.1935.02250240002001

10. Gibbs FA, Gibbs EL, Lennox WG. Epilepsy: a paroxysmal cerebral dysrhythmia. Brain (1937) 60:377-88. doi:10.1093/brain/60.4.377

11. Weir B. The morphology of the spike-wave complex. Electroencephalogr Clin Neurophysiol (1965) 19(3):284-90. doi:10.1016/0013-4694(65)90208-7

12. Blume WT, Lemieux JF. Morphology of spikes in spike-and-wave complexes. Electroencephalogr Clin Neurophysiol (1988) 69(6):508-15. doi:10.1016/0013-4694(88)90162-9 of provoking stimuli such as sleep deprivation, intermittent photic stimulation, hyperventilation, FOS, and reflex triggers during EEG recording can help increase the diagnostic yield. Some EEG features help differentiation among electroclinical syndromes. However, it should be emphasized that such differences are also influenced by several confounding variables including sex, age, state of alertness, activation methods, technical factors, and antiepileptic drug therapy.

\section{ETHICS STATEMENT}

This study was conducted with approvals from the Human Research Ethics Committees of Monash Health and St. Vincent's Hospital, Melbourne.

\section{AUTHOR CONTRIBUTIONS}

US: study concept and design, literature search, drafting, and critical revision of the manuscript. MC and WD: study concept, critical revision of the manuscript.

13. Seneviratne U, Cook M, D'Souza W. Consistent topography and amplitude symmetry are more typical than morphology of epileptiform discharges in genetic generalized epilepsy. Clin Neurophysiol (2016) 127(2):1138-46. doi:10.1016/j.clinph.2015.08.019

14. Lemieux JF, Blume WT. Topographical evolution of spike-wave complexes. Brain Res (1986) 373(1-2):275-87. doi:10.1016/0006-8993(86)90342-2

15. Clemens B, Bessenyei M, Piros P, Toth M, Seress L, Kondakor I. Characteristic distribution of interictal brain electrical activity in idiopathic generalized epilepsy. Epilepsia (2007) 48(5):941-9. doi:10.1111/j.1528-1167. 2007.01030.x

16. Rodin E, Ancheta O. Cerebral electrical fields during petit mal absences. Electroencephalogr Clin Neurophysiol (1987) 66(6):457-66. doi:10.1016/0013-4694(87)90092-7

17. Holmes MD, Quiring J, Tucker DM. Evidence that juvenile myoclonic epilepsy is a disorder of frontotemporal corticothalamic networks. Neuroimage (2010) 49(1):80-93. doi:10.1016/j.neuroimage.2009.08.004

18. da Silva Braga AM, Fujisao EK, Betting LE. Analysis of generalized interictal discharges using quantitative EEG. Epilepsy Res (2014) 108(10):1740-7. doi:10.1016/j.eplepsyres.2014.09.004

19. Delgado-Escueta AV, Enrile-Bacsal F. Juvenile myoclonic epilepsy of Janz. Neurology (1984) 34(3):285-94. doi:10.1212/WNL.34.3.285

20. Panayiotopoulos CP, Obeid T, Waheed G. Differentiation of typical absence seizures in epileptic syndromes. A video EEG study of 224 seizures in 20 patients. Brain (1989) 112(Pt 4):1039-56. doi:10.1093/brain/112.4.1039

21. Markand ON. Lennox-Gastaut syndrome (childhood epileptic encephalopathy). J Clin Neurophysiol (2003) 20(6):426-41. doi:10.1097/00004691200311000-00001

22. Markand ON. Pearls, perils, and pitfalls in the use of the electroencephalogram. Semin Neurol (2003) 23(1):7-46. doi:10.1055/s-2003-40750

23. Kasteleijn-Nolst Trenite DG, Guerrini R, Binnie CD, Genton P. Visual sensitivity and epilepsy: a proposed terminology and classification for clinical and EEG phenomenology. Epilepsia (2001) 42(5):692-701. doi:10.1046/j.1528-1157.2001.30600.x

24. Puglia JF, Brenner RP, Soso MJ. Relationship between prolonged and self-limited photoparoxysmal responses and seizure incidence: study and review. J Clin Neurophysiol (1992) 9(1):137-44. doi:10.1097/00004691-19920100000015

25. Gregory RP, Oates T, Merry RT. Electroencephalogram epileptiform abnormalities in candidates for aircrew training. Electroencephalogr Clin Neurophysiol (1993) 86(1):75-7. doi:10.1016/0013-4694(93)90069-8

26. Kooi KA, Thomas MH, Mortenson FN. Photoconvulsive and photomyoclonic responses in adults. An appraisal of their clinical significance. Neurology (1960) 10:1051-8. doi:10.1212/WNL.10.12.1051 
27. Brandt H, Brandt S, Vollmond K. EEG response to photic stimulation in 120 normal children. Epilepsia (1961) 2:313-7.

28. Panayiotopoulos CP. Syndromes of idiopathic generalized epilepsies not recognized by the international league against epilepsy. Epilepsia (2005) 46(Suppl 9):57-66. doi:10.1111/j.1528-1167.2005.00314.x

29. Panayiotopoulos CP. Fixation-off, scotosensitive, and other visual-related epilepsies. Adv Neurol (1998) 75:139-57.

30. Koutroumanidis M, Tsatsou K, Sanders S, Michael M, Tan SV, Agathonikou A, et al. Fixation-off sensitivity in epilepsies other than the idiopathic epilepsies of childhood with occipital paroxysms: a 12-year clinical-video EEG study. Epileptic Disord (2009) 11(1):20-36. doi:10.1684/epd.2009.0235

31. Agathonikou A, Koutroumanidis M, Panayiotopoulos CP. Fixation-off (Scoto) sensitivity combined with photosensitivity. Epilepsia (1998) 39(5):552-5. doi:10.1111/j.1528-1157.1998.tb01419.x

32. Niedermeyer E. Sleep electroencephalograms in petit mal. Arch Neurol (1965) 12:625-30. doi:10.1001/archneur.1965.00460300073010

33. Niedermeyer E. Primary (idiopathic) generalized epilepsy and underlying mechanisms. Clin Electroencephalogr (1996) 27(1):1-21. doi:10.1177/155005949602700103

34. Seneviratne U, Cook M, D'Souza W. Epileptiform K-complexes and sleep spindles: an underreported phenomenon in genetic generalized epilepsy. J Clin Neurophysiol (2016) 33(2):156-61. doi:10.1097/WNP.0000000000000239

35. Riviello JJ Jr, Foley CM. The epileptiform significance of intermittent rhythmic delta activity in childhood. J Child Neurol (1992) 7(2):156-60. doi:10.1177/088307389200700204

36. Sadleir LG, Farrell K, Smith S, Connolly MB, Scheffer IE. Electroclinical features of absence seizures in childhood absence epilepsy. Neurology (2006) 67(3):413-8. doi:10.1212/01.wnl.0000228257.60184.82

37. Janz D. Epilepsy with impulsive petit mal (juvenile myoclonic epilepsy). Acta Neurol Scand (1985) 72(5):449-59. doi:10.1111/j.1600-0404.1985. tb00900.x

38. Hrachovy RA, Frost JD Jr. The EEG in selected generalized seizures. J Clin Neurophysiol (2006) 23(4):312-32. doi:10.1097/01.wnp.0000228496.66246. e000004691-200608000-00005

39. Drury I, Henry TR. Ictal patterns in generalized epilepsy. J Clin Neurophysiol (1993) 10(3):268-80. doi:10.1097/00004691-199307000-00003

40. ILAE. Proposal for revised clinical and electroencephalographic classification of epileptic seizures. From the commission on classification and terminology of the international league against epilepsy. Epilepsia (1981) 22(4):489-501. doi:10.1111/j.1528-1157.1981.tb06159.x

41. Bureau M, Tassinari CA. Epilepsy with myoclonic absences. Brain Dev (2005) 27(3):178-84. doi:10.1016/j.braindev.2004.01.008

42. Giannakodimos S, Panayiotopoulos CP. Eyelid myoclonia with absences in adults: a clinical and video-EEG study. Epilepsia (1996) 37(1):36-44. doi:10.1111/j.1528-1157.1996.tb00509.x

43. Lombroso CT. Consistent EEG focalities detected in subjects with primary generalized epilepsies monitored for two decades. Epilepsia (1997) 38(7):797-812. doi:10.1111/j.1528-1157.1997.tb01467.x

44. Matur Z, Baykan B, Bebek N, Gurses C, Altindag E, Gokyigit A. The evaluation of interictal focal EEG findings in adult patients with absence seizures. Seizure (2009) 18(5):352-8. doi:10.1016/j.seizure.2009.01.007

45. Panayiotopoulos CP, Obeid T, Tahan AR. Juvenile myoclonic epilepsy: a 5-year prospective study. Epilepsia (1994) 35(2):285-96. doi:10.1111/ j.1528-1157.1994.tb02432.x

46. Panayiotopoulos CP, Tahan R, Obeid T. Juvenile myoclonic epilepsy: factors of error involved in the diagnosis and treatment. Epilepsia (1991) 32(5):672-6. doi:10.1111/j.1528-1157.1991.tb04708.x

47. Seneviratne U, Cook M, D'Souza W. Focal abnormalities in idiopathic generalized epilepsy: a critical review of the literature. Epilepsia (2014) 55:1157-69. doi:10.1111/epi.12688

48. Seneviratne U, Hepworth G, Cook M, D'Souza W. Atypical EEG abnormalities in genetic generalized epilepsies. Clin Neurophysiol (2016) 127(1):214-20. doi:10.1016/j.clinph.2015.05.031

49. Martins da Silva A, Aarts JH, Binnie CD, Laxminarayan R, Lopes da Silva FH, Meijer JW, et al. The circadian distribution of interictal epileptiform EEG activity. Electroencephalogr Clin Neurophysiol (1984) 58(1):1-13. doi:10.1016/0013-4694(84)90195-0

50. Halasz P, Filakovszky J, Vargha A, Bagdy G. Effect of sleep deprivation on spike-wave discharges in idiopathic generalised epilepsy: a 4 x 24 h continuous long term EEG monitoring study. Epilepsy Res (2002) 51(1-2):123-32. doi:10.1016/S0920-1211(02)00123-7

51. Labate A, Ambrosio R, Gambardella A, Sturniolo M, Pucci F, Quattrone A. Usefulness of a morning routine EEG recording in patients with juvenile myoclonic epilepsy. Epilepsy Res (2007) 77(1):17-21. doi:10.1016/j. eplepsyres.2007.07.010

52. Dhanuka AK, Jain BK, Daljit S, Maheshwari D. Juvenile myoclonic epilepsy: a clinical and sleep EEG study. Seizure (2001) 10(5):374-8. doi:10.1053/ seiz.2001.0522

53. Fittipaldi F, Curra A, Fusco L, Ruggieri S, Manfredi M. EEG discharges on awakening: a marker of idiopathic generalized epilepsy. Neurology (2001) 56(1):123-6. doi:10.1212/WNL.56.1.123

54. Seneviratne U, Boston RC, Cook M, D'Souza W. Temporal patterns of epileptiform discharges in genetic generalized epilepsies. Epilepsy Behav (2016) 64(Pt A):18-25. doi:10.1016/j.yebeh.2016.09.018

55. Wirrell EC, Camfield PR, Gordon KE, Camfield CS, Dooley JM, Hanna BD. Will a critical level of hyperventilation-induced hypocapnia always induce an absence seizure? Epilepsia (1996) 37(5):459-62. doi:10.1111/ j.1528-1157.1996.tb00592.x

56. Dalby MA. Epilepsy and 3 per second spike and wave rhythms. A clinical, electroencephalographic and prognostic analysis of 346 patients. Acta Neurol Scand (1969) Suppl 40:183.

57. Holmes MD, Dewaraja AS, Vanhatalo S. Does hyperventilation elicit epileptic seizures? Epilepsia (2004) 45(6):618-20. doi:10.1111/ j.0013-9580.2004.63803.x

58. Zifkin BG, Kasteleijn-Nolst Trenite D. Reflex epilepsy and reflex seizures of the visual system: a clinical review. Epileptic Disord (2000) 2(3): 129-36.

59. Radhakrishnan K, St Louis EK, Johnson JA, McClelland RL, Westmoreland BF, Klass DW. Pattern-sensitive epilepsy: electroclinical characteristics, natural history, and delineation of the epileptic syndrome. Epilepsia (2005) 46(1):48-58. doi:10.1111/j.0013-9580.2005.26604.x

60. Prasad M, Arora M, Abu-Arafeh I, Harding G. 3D movies and risk of seizures in patients with photosensitive epilepsy. Seizure (2012) 21(1):49-50. doi:10.1016/j.seizure.2011.08.012

61. Goossens LA, Andermann F, Andermann E, Remillard GM. Reflex seizures induced by calculation, card or board games, and spatial tasks: a review of 25 patients and delineation of the epileptic syndrome. Neurology (1990) 40(8):1171-6. doi:10.1212/WNL.40.8.1171

62. Matsuoka H, Takahashi T, Sasaki M, Matsumoto K, Yoshida S, Numachi Y, et al. Neuropsychological EEG activation in patients with epilepsy. Brain (2000) 123(Pt 2):318-30. doi:10.1093/brain/123.2.318

63. Ferlazzo E, Zifkin BG, Andermann E, Andermann F. Cortical triggers in generalized reflex seizures and epilepsies. Brain (2005) 128(Pt 4):700-10. doi:10.1093/brain/awh446

64. Vierck E, Cauley R, Kugler SL, Mandelbaum DE, Pal DK, Durner M. Polyspike and waves do not predict generalized tonic-clonic seizures in childhood absence epilepsy. J Child Neurol (2010) 25(4):475-81. doi: $10.1177 / 0883073809341665$

65. Vorderwulbecke BJ, Kowski AB, Kirschbaum A, Merkle H, Senf P, Janz D, et al. Long-term outcome in adolescent-onset generalized genetic epilepsies. Epilepsia (2017) 58(7):1244-50. doi:10.1111/epi.13761

66. Seneviratne U, Hepworth G, Cook M, D’Souza W. Can EEG differentiate among syndromes in genetic generalized epilepsy? J Clin Neurophysiol (2017) 34(3):213-21. doi:10.1097/WNP.0000000000000358

67. Montalenti E, Imperiale D, Rovera A, Bergamasco B, Benna P. Clinical features, EEG findings and diagnostic pitfalls in juvenile myoclonic epilepsy: a series of 63 patients. J Neurol Sci (2001) 184(1):65-70. doi:10.1016/S0022510X(00)00496-2

68. Sadleir LG, Scheffer IE, Smith S, Carstensen B, Carlin J, Connolly MB, et al. Factors influencing clinical features of absence seizures. Epilepsia (2008) 49(12):2100-7. doi:10.1111/j.1528-1167.2008.01708.x

69. Meeren HK, Pijn JP, Van Luijtelaar EL, Coenen AM, Lopes da Silva FH. Cortical focus drives widespread corticothalamic networks during spontaneous absence seizures in rats. J Neurosci (2002) 22(4):1480-95.

70. Bancaud J, Talairach J, Morel P, Bresson M, Bonis A, Geier S, et al. "Generalized" epileptic seizures elicited by electrical stimulation of the frontal lobe in man. Electroencephalogr Clin Neurophysiol (1974) 37(3):275-82. doi:10.1016/0013-4694(74)90031-5 
71. Holmes MD, Brown M, Tucker DM. Are "generalized" seizures truly generalized? Evidence of localized mesial frontal and frontopolar discharges in absence. Epilepsia (2004) 45(12):1568-79. doi:10.1111/j.0013-9580.2004. 23204.x

72. Tucker DM, Brown M, Luu P, Holmes MD. Discharges in ventromedial frontal cortex during absence spells. Epilepsy Behav (2007) 11(4):546-57. doi:10.1016/j.yebeh.2007.04.023

73. Stefan H, Paulini-Ruf A, Hopfengartner R, Rampp S. Network characteristics of idiopathic generalized epilepsies in combined MEG/EEG. Epilepsy Res (2009) 85(2-3):187-98. doi:10.1016/j.eplepsyres.2009.03.015

74. Sakurai K, Takeda Y, Tanaka N, Kurita T, Shiraishi H, Takeuchi F, et al. Generalized spike-wave discharges involve a default mode network in patients with juvenile absence epilepsy: a MEG study. Epilepsy Res (2010) 89(2-3):176-84. doi:10.1016/j.eplepsyres.2009.12.004

75. Hamandi K, Salek-Haddadi A, Laufs H, Liston A, Friston K, Fish DR, et al. EEG-fMRI of idiopathic and secondarily generalized epilepsies. Neuroimage (2006) 31(4):1700-10. doi:10.1016/j.neuroimage.2006.02.016

76. Ilmoniemi RJ, Kicic D. Methodology for combined TMS and EEG. Brain Topogr (2010) 22(4):233-48. doi:10.1007/s10548-009-0123-4

77. Kimiskidis VK, Tsimpiris A, Ryvlin P, Kalviainen R, Koutroumanidis M, Valentin A, et al. TMS combined with EEG in genetic generalized epilepsy: a phase II diagnostic accuracy study. Clin Neurophysiol (2017) 128(2):367-81. doi:10.1016/j.clinph.2016.11.013

78. Kugiumtzis D, Kimiskidis VK. Direct causal networks for the study of transcranial magnetic stimulation effects on focal epileptiform discharges. Int J Neural Syst (2015) 25(5):1550006. doi:10.1142/S0129065715500069

79. Fadini T, Nitsche M, Paulus W. Tracing origin and propagation areas of epileptic activity by combining TMS and EEG source analysis in generalized epilepsy. Epilepsia (2009) 50:186-7.

80. Bernhardt BC, Bonilha L, Gross DW. Network analysis for a network disorder: the emerging role of graph theory in the study of epilepsy. Epilepsy Behav (2015) 50:162-70. doi:10.1016/j.yebeh.2015.06.005

81. Lee C, Im CH, Koo YS, Lim JA, Kim TJ, Byun JI, et al. Altered network characteristics of spike-wave discharges in juvenile myoclonic epilepsy. Clin EEG Neurosci (2017) 48(2):111-7. doi:10.1177/1550059415621831

82. Chowdhury FA, Woldman W, FitzGerald TH, Elwes RD, Nashef L, Terry JR, et al. Revealing a brain network endophenotype in families with idiopathic generalised epilepsy. PLoS One (2014) 9(10):e110136. doi:10.1371/journal. pone. 0110136

83. Stefan H, Lopes da Silva FH. Epileptic neuronal networks: methods of identification and clinical relevance. Front Neurol (2013) 4:8. doi:10.3389/ fneur.2013.00008

84. Angus-Leppan H. Seizures and adverse events during routine scalp electroencephalography: a clinical and EEG analysis of 1000 records. Clin Neurophysiol (2007) 118(1):22-30. doi:10.1016/j.clinph.2006.08.014

85. Krumholz A, Wiebe S, Gronseth G, Shinnar S, Levisohn P, Ting T, et al. Practice parameter: evaluating an apparent unprovoked first seizure in adults (an evidence-based review): report of the quality standards subcommittee of the American Academy of Neurology and the American Epilepsy Society. Neurology (2007) 69(21):1996-2007. doi:10.1212/01.wnl. 0000285084.93652 .43

86. Betting LE, Mory SB, Lopes-Cendes I, Li LM, Guerreiro MM, Guerreiro $\mathrm{CA}$, et al. EEG features in idiopathic generalized epilepsy: clues to diagnosis. Epilepsia (2006) 47(3):523-8. doi:10.1111/j.1528-1167.2006.00462.x

87. Seneviratne U, Rahman Z, Diamond A, Brusco M. The yield and clinical utility of outpatient short-term video-electroencephalographic monitoring: a five-year retrospective study. Epilepsy Behav (2012) 25(3):303-6. doi:10.1016/j.yebeh.2012.08.018

88. Ghougassian DF, d'Souza W, Cook MJ, O’Brien TJ. Evaluating the utility of inpatient video-EEG monitoring. Epilepsia (2004) 45(8):928-32. doi:10.1111/j.0013-9580.2004.51003.x

89. Ellingson RJ, Wilken K, Bennett DR. Efficacy of sleep deprivation as an activation procedure in epilepsy patients. J Clin Neurophysiol (1984) 1(1):83-101. doi:10.1097/00004691-198401000-00005

90. De Marchi LR, Corso JT, Zetehaku AC, Uchida CGP, Guaranha MSB, Yacubian EMT. Efficacy and safety of a video-EEG protocol for genetic generalized epilepsies. Epilepsy Behav (2017) 70(Pt A):187-92. doi:10.1016/j. yebeh.2017.03.029
91. Keezer MR, Simard-Tremblay E, Veilleux M. The diagnostic accuracy of prolonged ambulatory versus routine EEG. Clin EEG Neurosci (2016) 47(2):157-61. doi:10.1177/1550059415607108

92. Faulkner HJ, Arima H, Mohamed A. The utility of prolonged outpatient ambulatory EEG. Seizure (2012) 21(7):491-5. doi:10.1016/j.seizure.2012.04.015

93. Seneviratne U, Mohamed A, Cook M, D'Souza W. The utility of ambulatory electroencephalography in routine clinical practice: a critical review. Epilepsy Res (2013) 105(1-2):1-12. doi:10.1016/j.eplepsyres.2013.02.004

94. Scheepers B, Clough P, Pickles C. The misdiagnosis of epilepsy: findings of a population study. Seizure (1998) 7(5):403-6. doi:10.1016/ S1059-1311(05)80010-X

95. Smith D, Defalla BA, Chadwick DW. The misdiagnosis of epilepsy and the management of refractory epilepsy in a specialist clinic. Q J Med (1999) 92(1):15-23. doi:10.1093/qjmed/92.1.15

96. Okubo Y, Matsuura M, Asai T, Asai K, Kato M, Kojima T, et al. Epileptiform EEG discharges in healthy children: prevalence, emotional and behavioral correlates, and genetic influences. Epilepsia (1994) 35(4):832-41. doi:10.1111/ j.1528-1157.1994.tb02520.x

97. Delgado-EscuetaAV,GreenbergD, WeissbeckerK,Liu A,TreimanL,SparkesR, et al. Gene mapping in the idiopathic generalized epilepsies: juvenile myoclonic epilepsy, childhood absence epilepsy, epilepsy with grand mal seizures, and early childhood myoclonic epilepsy. Epilepsia (1990) 31(Suppl 3): S19-29. doi:10.1111/j.1528-1157.1990.tb05855.x

98. Jayalakshmi SS, Mohandas S, Sailaja S, Borgohain R. Clinical and electroencephalographic study of first-degree relatives and probands with juvenile myoclonic epilepsy. Seizure (2006) 15(3):177-83. doi:10.1016/j. seizure.2005.12.011

99. Tukel $\mathrm{K}$, Jasper $\mathrm{H}$. The electroencephalogram in parasagittal lesions. Electroencephalogr Clin Neurophysiol (1952) 4(4):481-94. doi:10.1016/ 0013-4694(52)90079-5

100. Blume WT, Pillay N. Electrographic and clinical correlates of secondary bilateral synchrony. Epilepsia (1985) 26(6):636-41. doi:10.1111/j.1528-1157.1985. tb05704.x

101. Quesney LF. Preoperative electroencephalographic investigation in frontal lobe epilepsy: electroencephalographic and electrocorticographic recordings. Can J Neurol Sci (1991) 18(4 Suppl):559-63. doi:10.1017/S0317167100032698

102. Jayakar P, Duchowny M, Resnick TJ, Alvarez LA. Localization of seizure foci: pitfalls and caveats. JClin Neurophysiol (1991) 8(4):414-31. doi:10.1097/00004691-199110000-00006

103. Jayakar P, Duchowny MS, Resnick TJ, Alvarez LA. Localization of epileptogenic foci using a simple reference-subtraction montage to document small interchannel time differences. J Clin Neurophysiol (1991) 8(2):212-5. doi:10.1097/00004691-199104000-00009

104. Gotman J. Measurement of small time differences between EEG channels: method and application to epileptic seizure propagation. Electroencephalogr Clin Neurophysiol (1983) 56(5):501-14. doi:10.1016/0013-4694(83)90235-3

105. Seneviratne U. Rational manipulation of digital EEG: pearls and pitfalls. J Clin Neurophysiol (2014) 31(6):507-16. doi:10.1097/WNP.0000000000000128

106. Klass DW, Westmoreland BF. Nonepileptogenic epileptiform electroencephalographic activity. Ann Neurol (1985) 18(6):627-35. doi:10.1002/ ana.410180602

107. Hughes JR. Two forms of the 6/sec spike and wave complex. Electroencephalogr Clin Neurophysiol (1980) 48(5):535-50. doi:10.1016/0013-4694(80)90289-8

108. Schmidt H, Petkov G, Richardson MP, Terry JR. Dynamics on networks: the role of local dynamics and global networks on the emergence of hypersynchronous neural activity. PLoS Comput Biol (2014) 10(11):e1003947. doi:10.1371/journal.pcbi.1003947

Conflict of Interest Statement: The authors declare that the research was conducted in the absence of any commercial or financial relationships that could be construed as a potential conflict of interest.

Copyright $\odot 2017$ Seneviratne, Cook and D'Souza. This is an open-access article distributed under the terms of the Creative Commons Attribution License (CC BY). The use, distribution or reproduction in other forums is permitted, provided the original author(s) or licensor are credited and that the original publication in this journal is cited, in accordance with accepted academic practice. No use, distribution or reproduction is permitted which does not comply with these terms. 